\title{
Investigation of NiTi based damper effects in bridge cables vibration response: Damping capacity and stiffness changes
}

\author{
Guillaume Helbert $^{\mathrm{a}, *}$, Lamine Dieng ${ }^{\mathrm{b}}$, Shabnam Arbab Chirani ${ }^{\mathrm{a}}$, Luc Saint-Sulpice ${ }^{\mathrm{a}}$, \\ Thibaut Lecompte ${ }^{\mathrm{c}}$, Sylvain Calloch ${ }^{\mathrm{d}}$, Philippe Pilvin ${ }^{\mathrm{c}}$ \\ a UEB, ENIB, IRDL (FRE 3744), Technopôle Brest-Iroise, Brest, France \\ ${ }^{\mathrm{b}}$ IFSTTAR, MAST, Bouguenais, France \\ c UEB, UBS, IRDL (FRE 3744), Lorient, France \\ ${ }^{\mathrm{d}}$ UEB, ENSTA Bretagne, IRDL (FRE 3744), Brest, France
}

Due to aerodynamic instabilities induced by combination of rain and wind, civil engineering cables are submitted to cyclic loadings during their whole operating life. To prevent them from fatigue issues, internal and external dampers are increasingly used.

Recently, innovative damping devices based on Shape Memory Alloys have demonstrated a true efficiency, thanks to their dissipation properties. Indeed, near-equiatomic Nickel-Titanium alloys (NiTi) present an interesting damping capacity due to a solid-solid displacive phase transformation of austenite into martensite. This transformation occurs under thermal and/or mechanical loadings.

Two different damping devices embedding NiTi wires are presented in this paper. Both are evaluated ad hoc, using a full-scale vibration cable bench under several loading and environment configurations. The effectiveness of the damping device has been demonstrated. A direct link has been made between the system "cable + damper" vibration response and NiTi behaviour. First, results show that several damping regimes observed during mitigation of the cable vibration amplitude are due to NiTi microstructural changes and phase transformations. Secondly, this paper demonstrates that stiffness and vibration frequency changes are governed by the NiTi stress-strain curve secant stiffness modulus.

\section{Introduction}

Cables are crucial parts of Civil Engineering structures. Cable vibrations are entailed by traffic, and by combination of wind and rain [1-5]. Civil Engineering cables (stay cables, hangers...) have a quite low intrinsic damping capacity (damping ratio less than $0.01 \%$ ). Thus, these structural cables are subjected to fatigue phenomenon, mainly near the anchorages, due to vibrations [6]. If the aerodynamic parameter of Scrouton $S_{\text {co }}$ (cf. Eq. (1)) is superior to 10, rain wind-induced instabilities can be prevented, a priori, according to the PTI Guide Specification and the Federal Highway administration [7]. It corresponds to a critical damping ratio value $\xi_{\text {rec }}^{c r}$ higher than $0.7 \%$ as recommanded in [7].

$S_{c 0}=\frac{\mu \xi}{\rho_{\text {air }} D^{2}}$

With $\mu$ the cable linear density $\left(16.1 \mathrm{~kg} \mathrm{~m}^{-1}\right), \rho_{\text {air }}$ the air density $\left(1.225 \mathrm{~kg} \mathrm{~m}^{-3}\right.$, at $15^{\circ} \mathrm{C}$ and at sea level), and $D$ the cable diameter. To increase structural damping ratio of cables, several solutions are currently in service:

- Internal passive dampers, which link cables to the whole structure. Internal dampers are based on dissipation properties of materials (specially formulated neoprene), viscous friction, or dry friction between two solids. Setting-up of internal dampers have ended parametric vibrations on Badajoz bridge (Spain) [8].

- "Cross-tied" dampers, which ensure connection between stay cables, using wires ties in order to avoid some vibration modes and to move modal frequencies far from the resonance frequency of the whole structure [7]. Fred Harman bridge (USA) has taken advantage of local increase in stiffness, thanks to "cross-tied" dampers [8].

- External passive dampers, which exert a transverse damping force on the cable, near its anchorages $[9,10]$. Most of them are viscous dampers [11].

\footnotetext{
* Corresponding author.

E-mail address: helbert@enib.fr (G. Helbert).
} 
To fight against transverse vibrations of a cable, the latter is better suited. According to [11], an optimal viscous transverse damper attached at a distance of about 2-4\% from one of the supports performs a damping ratio of $\xi_{o p t}^{a}=a /(2 L)$ (with $a$ the damper location along a $L$ long cable). One have to notice that passive and semi-active negative stiffness dampers also perform a good efficiency $[12,13]$. However, the major weakpoint of viscous damper devices is their working ranges, in terms of amplitude and frequencies. Excessive displacement rate of cables can induce high loading values to its anchorages, until fracture. For instance, this event was observed in Öresund Bridge (linking Denmark to Sweden) [8].

To overcome these limitations, new devices based on Shape Memory Alloys (SMA) were developped during the last decade for building and domestic house [14]. SMA are part of the "smart material" class [15]: they are able to accommodate their response (mechanical and/or thermal behaviours) to stimulations (natural or induced). Near-equiatomic Nickel-Titanium (NiTi) based SMA have interesting properties thanks to the martensite solid-solid displacive transformation and their functional properties (fatigue resistance and corrosion resistance). Strong damping capacity of NiTi alloys represents their capability to convert mechanical energy into heat, during vibrations amplitude mitigation or shock absorption. Thus, NiTi based dampers have shown first promising results $[16,14,17]$.

Considering a strongly non-linear working of the damper due to embedded material behaviour and a localized effect on the cable, this problem is very complex. Thus, realistic experiments at full scale seem to be necessary to answer the following questions:

1. Are the presented SMA-based dampers efficient and how to evaluate their efficiency under realistic conditions over a cable structure (bridge cable equipped with damper)?

2. What is the effect of material dissipation mechanisms on cable structure damping?

3. What is the effect of stiffness increase on dynamic response of the cable structure?

This paper is divided into 4 parts. In a first part, the respective Nickel-Titanium based SMA is studied, in order to take advantage of its damping properties, when embedded in a damping device. In a second part, two NiTi based damper devices (so-called "1-floor" and "2-floors" dampers) are developped. A full-scale Civil Engineering test and a posttreatment methodology are proposed in order to study their respective efficiency. A third part presents results, and more particularly the effects of testing temperature and damper technology on damping capacity. The link between material behaviour, damping capacity of the damper and stiffness changes of the whole structure is discussed in the last part, by analyzing data extracted from vibration signals.

\section{Material}

\subsection{Generalities on $S M A$}

The studied NiTi alloy was provided by Memry corporation (Connecticut, USA), which is a SAES group getters company (Italy), under the form of wire samples. Its chemical composition is detailed in Table 1 [17].

Two of tensile tests, presented in Fig. 1, illustrate the hysteretic behaviour of SMA, thanks to the stress-induced martensite transformation. Both tests were realized in the same conditions (testing temperature of $T=288 \mathrm{~K}$, strain rate of $0.005 \% \mathrm{~s}^{-1}$, sample working length of $L_{0}=130 \mathrm{~mm}$ ), apart from the imposed maximal strain amplitude of 1 or 3\%. The black curve (strain amplitude of 3\%) highlights martensite appearance. The grey one (strain amplitude of 1\%) highlights a thin loop hysteresis under the martensite transformation yield stress. "Circles" indicate starts of forward (solid circles) and reverse (empty
Table 1

Chemical analysis provided by the furnisher Memry Corporation (USA) according to requirements of ASTM F2063-05 replaced by F2063-12 since Dec. 1, 2012.

\begin{tabular}{lcc}
\hline Material composition & Requirement & Test Results \\
\hline Nickel & $54.5-57.0 \mathrm{wt} \%$ & $56.30 \mathrm{wt} \%$ \\
Titanium & Balance & Balance \\
Carbon & $500 \mathrm{ppm}$ maximum & $40 \mathrm{ppm}$ \\
Nitrogen + Oxygen & $0.050 \mathrm{wt} \%$ maximum & $0.0210 \mathrm{wt} \%$ \\
Cobalt & $0.050 \mathrm{wt} \%$ maximum & $<0.0050 \mathrm{wt} \%$ \\
Copper & $0.010 \mathrm{wt} \%$ maximum & $<0.0050 \mathrm{wt} \%$ \\
Chromium & $0.010 \mathrm{wt} \%$ maximum & $<0.0050 \mathrm{wt} \%$ \\
Hydrogen & $0.005 \mathrm{wt} \%$ maximum & $0.001 \mathrm{wt} \%$ \\
Niobium & $0.025 \mathrm{wt} \%$ maximum & $<0.0050 \mathrm{wt} \%$ \\
\hline
\end{tabular}

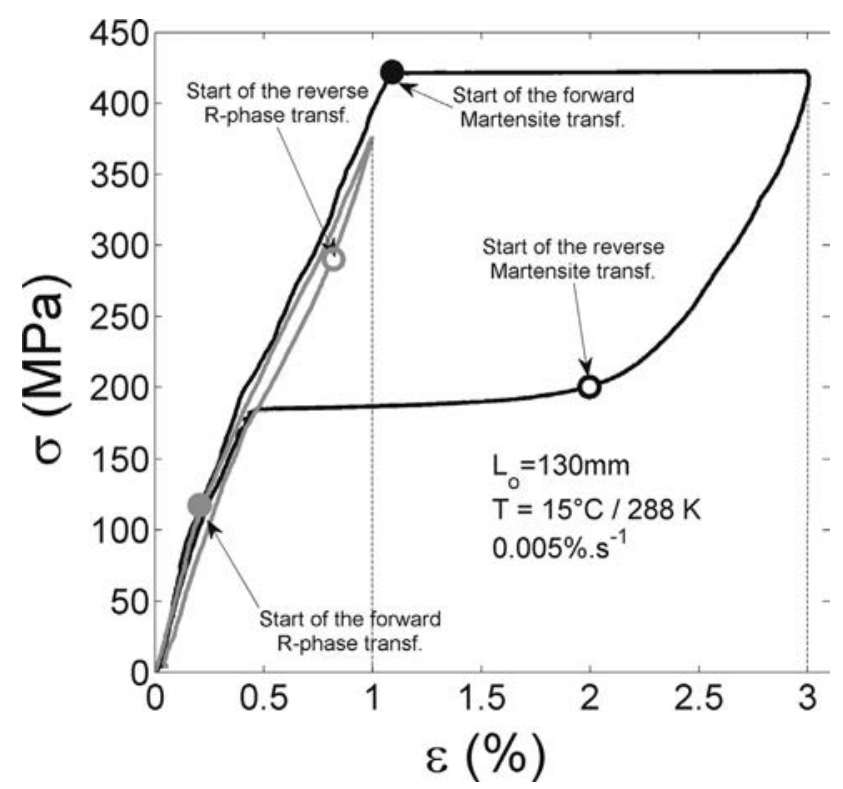

Fig. 1. Tensile tests at 1 and $3 \%$ of imposed strain.

circles) involved transformations used to build the Clausius-Clapeyron pseudo-diagram of the relative NiTi alloy, provided in Fig. 2. The identification process of transformations starts is explained in [18].

Several quasi-static tensile tests were conducted to build this pseudo-diagram, by measuring phase transformation stresses while changing testing temperature (controlled using values provided by the sensor located in the thermal chamber) and maximal imposed strain value [18]. The corresponding thermo-mechanical paths of previous tensile tests are represented by arrows in the pseudo-diagram. It is interesting to notice that an intermediate transformation (R-phase) occurs between austenite (parent phase) and martensite state, that explains the deviation from linearity before the martensite transformation yield stress in the black curve (cf. Fig. 1). That also explains the hysteretic behaviour illustrated by the grey curve (cf. Fig. 1), which does not exhibit martensite transformation.

\subsection{SMA dissipation properties}

Three main sources of dissipation that explain damping capacity of SMA were identified in $[19,20]$. They are closely related to material state:

1. A low dissipation is due to few microdefects and mobile interfaces in the parent austenitic phase (intrinsic term related to austenite).

2. A significant dissipation is due to mobility of martensite variants or several phases interfaces (intrinsic term related to martensite). This source is generally considered when the material is fully martensitic at testing temperature. Thus, dissipation is due to martensite 


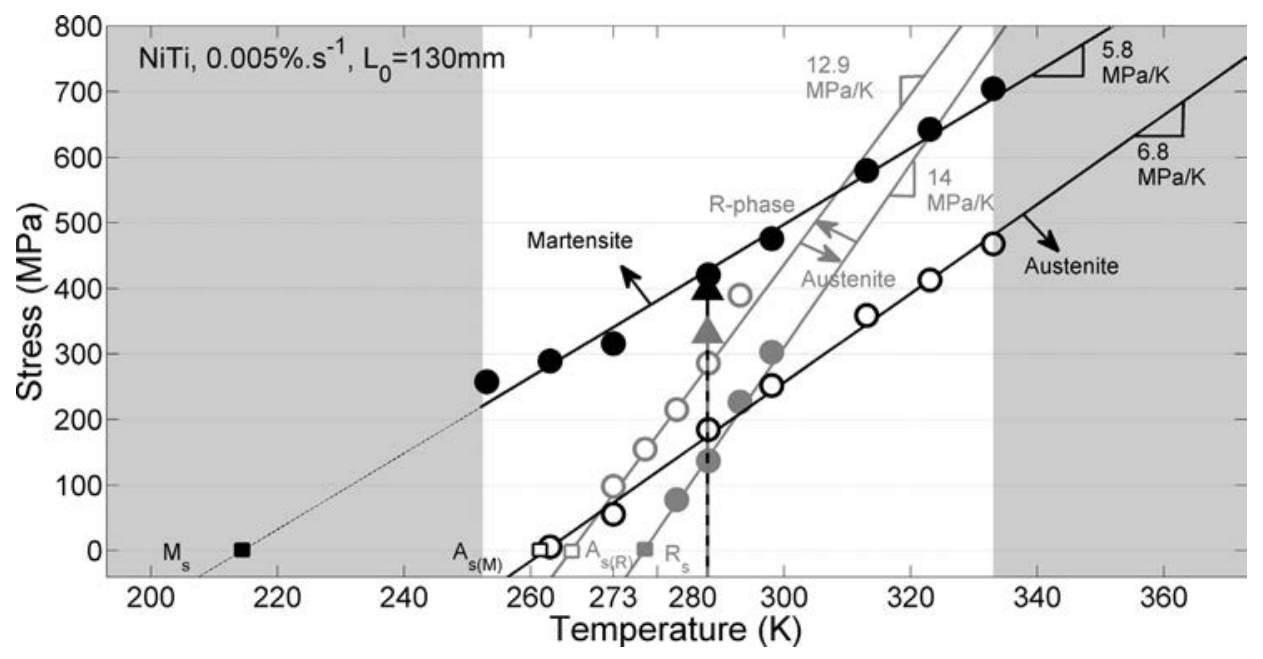

Fig. 2. Pseudo-diagram of studied NiTi alloy on the temperature range of [253-333] K.

variants detwinning.

3. A high dissipation is due to latent heat (phase transition term), released during stress-induced martensite transformation. The dissipated energy is size, frequency and history dependant according to [21]. One can notice that the two previous sources of dissipation can be involved during the martensite transformation process.

Thus, R-phase and the corresponding transformations are expected to be additional sources of dissipation.

Involved energies in SMA can be observed in the $\sigma-\varepsilon$ curve, from loop hysteresis area measurements under tensile loading (cf. Fig. 3, according to [22]). Furthermore, dissipated energy per unit volume $\Delta W$ (hysteresis loop area, cf Fig. 3), and maximal transformation strain energy per unit volume $W$ (area under the forward transformation curve) are related to loss factor $\eta$ and so intrinsic damping capacity of the material [20], according to Eq. (2). It is important to understand that the intrinsic damping capacity of the material, represented by $\eta$, has not the same meaning as the cable damping ratio $\xi$ provided in Eq. (1). The latter includes the dissipated energy of the cable in addition to the dissipated energy of the material embedded in the damper. However, highlighting of their link is one of the purposes of this study.

$\eta=\frac{1}{2 \pi} \frac{\Delta W}{W-\frac{1}{2} \Delta W}$

Effects of imposed testing conditions (temperature and strain rate)

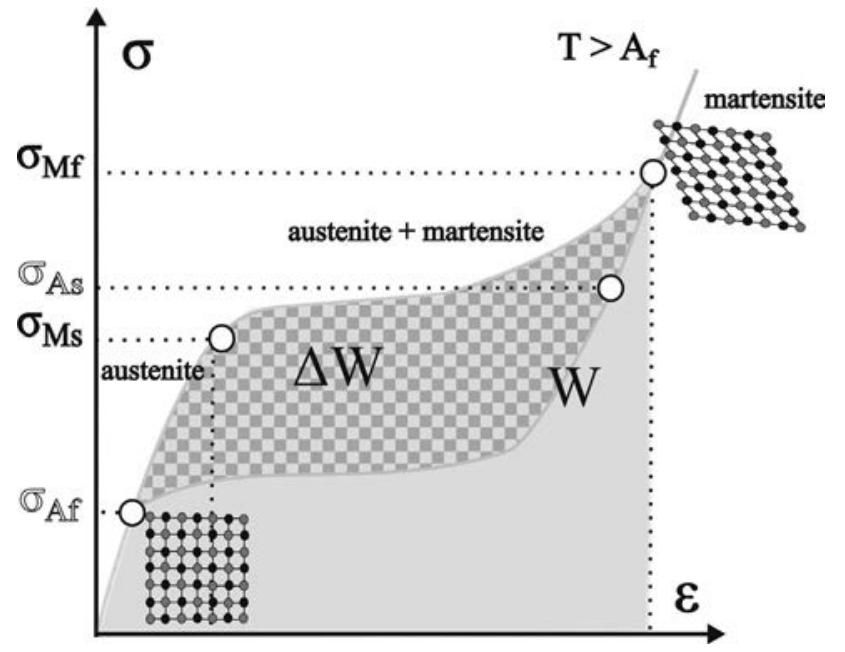

Fig. 3. Calculation of involved energies in superelastic SMA. on intrinsic damping capacity of the material are presented in Fig. 4a and $b$ ).

Results presented in Fig. 4a show that the testing temperature increase triggered a damping capacity decrease. In this figure, tests can be considered as quasi-statics, due to a very low imposed strain rate $\left(5.10^{-3} \% \mathrm{~s}^{-1}\right)$. Thus, material and ambient temperatures are assumed to be equal. Furthermore, R-phase transformation provided a non negligible intrinsic loss factor, despite a low dissipated energy, as revealed by the thin loop hysteresis area (cf. Fig. 1, curve associated to $\varepsilon_{\max }=1 \%$ ). It is due to a relatively low maximal transformation strain energy, involved in the calculation of the loss factor after expression (2). Curves shown in Fig. $4 \mathrm{~b}$ present a non monotonic effect of imposed strain rate on the damping capacity. Due to a strong thermomechanical coupling and an intrinsic dissipation, that induce material temperature changes from the ambient temperature, damping capacity changes non monotonically and non linearly with strain rate [23]. A detailed analysis on involved energies in this material is presented in [18], and it has shown a good agreement with results presented in other studies $[21,24]$. The maximum value of loss factor and the corresponding strain rate value are functions of transformation latent heat absorption/release and thermal exchanges between NiTi samples and surroundings (such as conduction through the anchorages or convection phenomenon, driven by speed rate of flowing air in [23]). The reader is refered to [25] for more details. The tensile tests used to build Fig. 4a and b were realized on as-furnished NiTi samples, to describe significant tendencies.

\section{Tests}

\subsection{SMA-based damper devices}

The principle of the two presented damping devices lies on the energy dissipation of NiTi wires submitted to tensile loadings. NiTibased SMA are known for their cyclic behaviour: residual strain is progressively induced by blocked martensite and created dislocations [26]. Before being embedded in any damper device, wires have to be trained in order to reach a stabilized mechanical behaviour and a stabilized stress-free wire length. Thus, the quantitative values presented in the previous section can not be directly used because the material will not be used in its initial state. Two $1.26 \mathrm{~m}$ long wires were trained over more than 100 cycles, with a very low frequency [17]. The length was chosen to reach a maximal relative elongation value of $2 \%$ during tests, in order to get a good compromise between high damping efficiency and high cycle fatigue life. The number of 2 wires was chosen to get an effective cross section area corresponding to a good compromise 


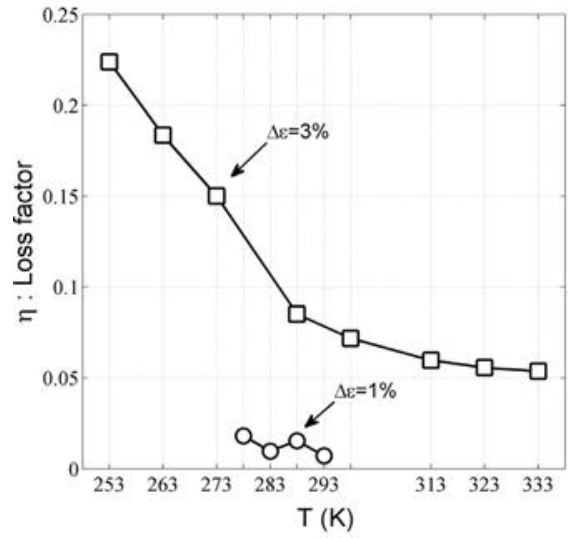

a)

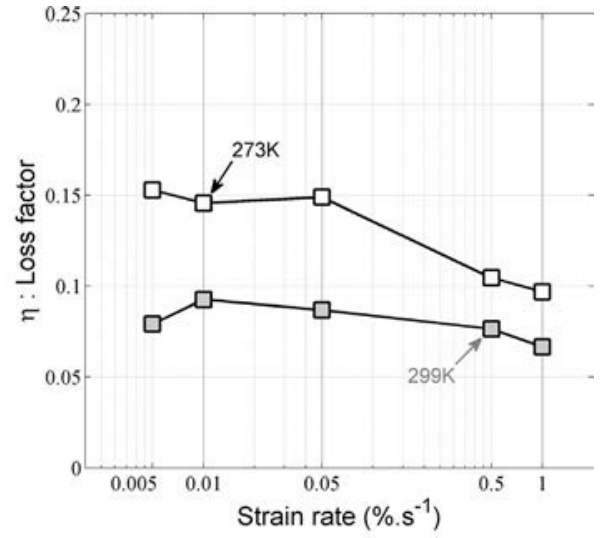

b)

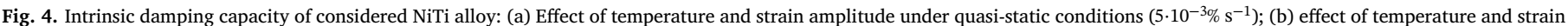
rate.

between high dissipated energy and low additional stiffness. Furthermore, an even number of wires ensures a good load balancing of the system.

Two versions of damping devices were developped and are described in Figs. 5 and 6.

- In the "1-floor" damper, NiTi wires are stretched due to plates and mechanical stops located at both extremities of each wire. One plate is clamped to the ground, whereas the other one is linked with the cable. Thus, the "1-floor" damper works in only one direction (when the cable is moving away from the clamping to the ground), but this system enables to avoid wires buckling.

- In the "2-floors" damper, an intermediate plate, linked with the cable, ensures alternative stretching between half-wires. In this case, the two external plates are fixed to the ground. Thus, the "2-floors" damper works in both directions and working length is divided by two when compared to the "1-floor" damper, for a given size of the device. This system also enables to avoid wires buckling: the working half-wires are active when loaded in tension thanks to unilateral jaws, while the remaining part of each wire is load free.

Three design parameters can modify damping efficiency: working length of wires, section and/or number of wires, and pre-strain of wires. The latter can be increased using a turnbuckle to change the length between the device clamping to the ground and the corresponding plate. In this case, a turnbuckle round corresponds to a displacement of $1 \mathrm{~mm}$.

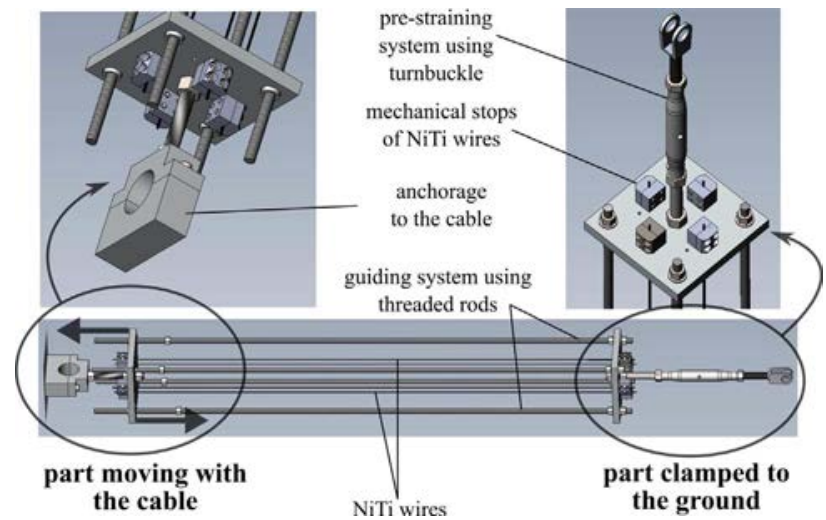

Fig. 5. Description of the "1-floor" SMA-based damper (in the configuration "4 wires").

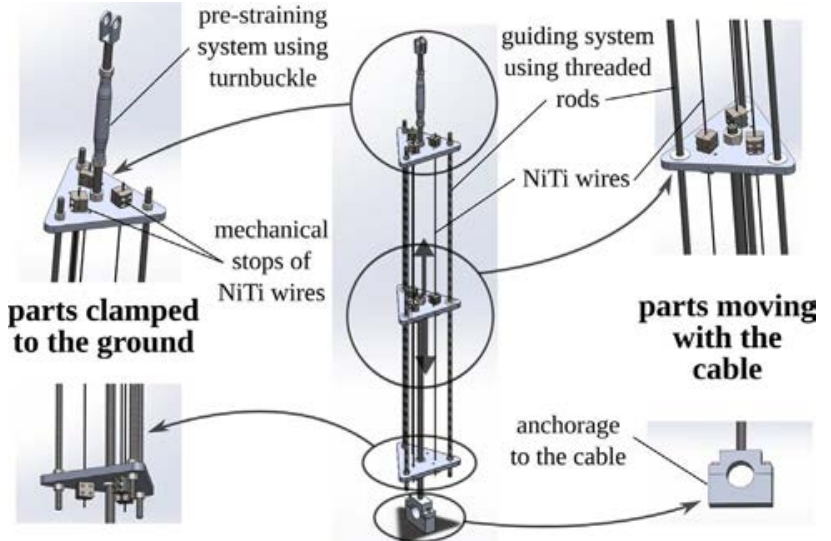

Fig. 6. Description of the "2-floors" SMA-based damper (in the configuration "3 wires").

\subsection{Test setting-up and configurations}

The cable vibration bench located at Ifsttar (Nantes - France) was used to measure the efficiency of the two studied damper devices. The cable length $L$ is of $50.5 \mathrm{~m}$, with a cross section of about $1934 \mathrm{~mm}^{2}$ and a linear density of $16.1 \mathrm{~kg} \mathrm{~m}^{-1}$. Its mechanical composition is detailed in [17]. According to the PTI Guide Specification, the critical damping ratio to prevent rain-wind instabilities is estimated to be $\xi_{\text {Ifsttar }}^{c r}>0.23 \%$ by taking into account Ifsttar cable characteristics. An axial tensile force of about $900 \mathrm{kN}$ was exerted to the cable, using a hydraulic jack.

Several configurations of vibration tests were studied using "1floor" and "2-floors" dampers (cf. Table 2). A vertical force was applied at $L / 2, L / 4, L / 6$ or $L / 8$ to reach a force value of $4 \mathrm{kN}$, in the sense where

Table 2

Test case-studies using "1-floor" damper (* tests have also been realized using the " 2 floors" damper).

\begin{tabular}{|c|c|c|c|c|c|c|c|c|}
\hline Case-study & 1 & 2 & 3 & 4 & 5 & 6 & 7 & 8 \\
\hline Damper location & $\mathrm{L} / 2$ & $\mathrm{~L} / 2$ & $\mathrm{~L} / 2$ & $\mathrm{~L} / 2$ & $\mathrm{~L} / 4$ & $\mathrm{~L} / 4$ & $\mathrm{~L} / 4$ & $\mathrm{~L} / 4$ \\
\hline Excitation location & $\mathrm{L} / 2$ & $\mathrm{~L} / 4$ & $\mathrm{~L} / 6$ & $\mathrm{~L} / 8$ & $\mathrm{~L} / 2$ & $\mathrm{~L} / 4$ & $\mathrm{~L} / 6$ & $\mathrm{~L} / 8$ \\
\hline "Low" temperature & Yes & Yes & Yes & No & No & No & No & No \\
\hline "High" temperature & Yes* $^{*}$ & Yes* $^{*}$ & Yes & Yes & Yes* $^{*}$ & Yes* & Yes & Yes \\
\hline Case-study & 9 & 10 & 11 & 12 & 13 & 14 & 15 & 16 \\
\hline Damper location & $\mathrm{L} / 6$ & $\mathrm{~L} / 6$ & $\mathrm{~L} / 6$ & $\mathrm{~L} / 6$ & $\mathrm{~L} / 16$ & $\mathrm{~L} / 16$ & $\mathrm{~L} / 16$ & $\mathrm{~L} / 16$ \\
\hline Excitation location & $\mathrm{L} / 2$ & $\mathrm{~L} / 4$ & $\mathrm{~L} / 6$ & $\mathrm{~L} / 8$ & $\mathrm{~L} / 2$ & $\mathrm{~L} / 4$ & $\mathrm{~L} / 6$ & $\mathrm{~L} / 8$ \\
\hline "Low" temperature & No & No & No & No & Yes & Yes & Yes & Yes \\
\hline "High" temperature & Yes & Yes & Yes & Yes & Yes & Yes* & Yes & Yes \\
\hline
\end{tabular}


the "1-floor" damper does not work. In order to excite the cable at its natural frequency and at the corresponding first harmonics, the localized deviation was suddendly released. The damper was located at $L / 2, L / 4, L / 6$ or at $L / 16$, which is a more realistic but complex configuration.

Two laser sensors were set-up to measure the cable transverse displacement at $L / 4$ and $L / 16$. Moreover, an additional laser sensor was used to measure the distance between the plates embedded in the "1floor" damper, in order to estimate the wire tensile-induced elongation. Two accelerometers were set-up on the cable to calculate its relative displacement, at the damper and excitation locations. To check the reproducibility of the results, each test was realized twice at "high" temperature (summer season, temperature of about $20^{\circ} \mathrm{C}$ ). Some of them were also realized at "low" temperature (winter season, temperature of about $5^{\circ} \mathrm{C}$ ). A temperature probe was located in the bench and 2 thermocouples were located on one of the two NiTi wires.

All these case-studies can be compared to a corresponding configuration without any damper. Case-study 1 , at "low" temperature, was presented in [17]. In this paper, case-studies 2, 6 and 14 are studied. According to several studies, rain wind-induced vibration in bridge cables are dominated by the first in-plane modes $[27,28,8,29]$. Thus, the two first natural modes will be discussed: by locating the excitation at $\mathrm{L} / 4$, both first and second vibration modes will be highly involved. Additional modes can be expected on both sides of the damper device. Indeed, the damper locally increased bending stiffness of the cable and can be considered as a "smooth" clamping. Simplified schemes of studied configurations are given in Figs. 7 and 8.

As a preliminary study, the "1-floor" damper device was set-up at $L / 2$. Relative elongation (assumed to be macroscopic strain) of the wire according to the number of turnbuckle rounds is presented in Fig. 9. Two domains can be observed: a linear part from 0 to 5 rounds and a non linear part above 5 rounds. The plate linked with the cable moves with respect to the opposite plate by increasing the number of turnbuckle rounds. The cable transverse displacement is non linear and non monotonic because of the complex stranded-wires structure of the cable and the non-linear tensile stiffness of NiTi wires.

In what follows, the number of 4 turnbuckle rounds is adopted, which means an elongation of about $4 \mathrm{~mm}$. It ensures to not affect stranded-wires configuration and to reach a quasi fully austeno-R-phase state of NiTi, below $15^{\circ} \mathrm{C}$ (cf. Fig. 1a). Furthermore, the value is relatively close to the "transformation yield strain": higher dissipation is expected by increasing pre-strain value.

\subsection{Identification of modal parameters}

The dynamic response of the cable can be derived from the following differential equilibrium equation:

$$
\begin{aligned}
& E I \frac{\partial^{4} y(x, t)}{\partial x^{4}}-T_{0} \frac{\partial^{2} y(x, t)}{\partial x^{2}}-T(t) \frac{\partial^{2} y_{0}(x)}{\partial x^{2}}+c \frac{\partial y(x, t)}{\partial t}+\frac{\mu}{L} \frac{\partial^{2} y(x, t)}{\partial x^{2}} \\
& \quad=f(x, t)-f_{d} \delta\left(x-x_{d}\right)
\end{aligned}
$$

where $x \in[0, L]$ is the position along the cable, $t$ is the time, $y$ is the transverse displacement, $E I$ is the bending stiffness of the cable, $T_{0}$ is the static tension force in the cable, $T(t)$ is the dynamic tension induced by vibration, $c$ is the intrinsic damping coefficient per cable unit length, $y_{0}(x)$ is the static deflexion of the cable due to sag-effect, $f(x, t)$ is the

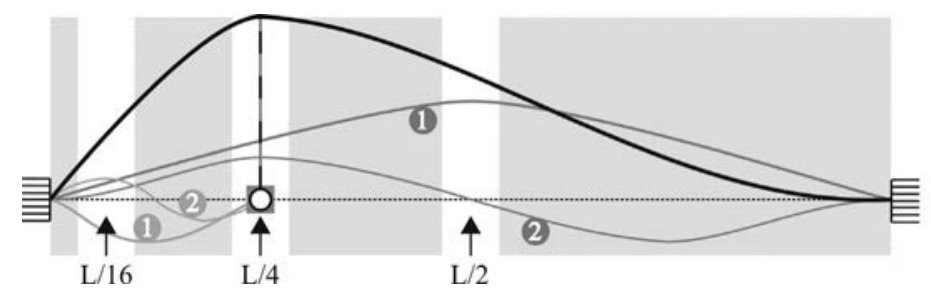

distributed external force applied on the cable, $f_{d}$ is the damping force due to the damper located at $x_{d}$ and $\delta$ is Dirac fonction. The equation solving provides transverse free displacement of a cable initially deviated of a distance $d$ :

$y(x, t)=\sum_{n=1}^{N} C_{n} \sin \left(\frac{n \pi x}{L}\right) \sin \left(2 \pi f_{n} \sqrt{1-\xi_{n}^{2}} t+\phi_{n}\right) \exp \left(-2 \pi f_{n} \xi_{n} t\right)$

where the $n$th natural frequency is given by Eq. (5), according to $[30,8]$ :

$f_{n}=\frac{n}{2 L} \sqrt{\frac{T}{\mu}}\left[1+2 \sqrt{\frac{E I}{T L^{2}}}+\left(4+\frac{n \pi^{2}}{2}\right) \frac{E I}{T L^{2}}\right]$

With,

$C_{n}=\frac{2 d}{\alpha(1-\alpha) n^{2} \pi^{2}} \sin (n \pi \alpha)$ and $\alpha=\frac{L-l}{L}$

where $l$ is the distance between the excitation location and one of the two anchorages and $L$ is the cable length.

Considering non-linear SMA mechanical behaviour and localized damping force on the cable, Eq. (4) is written in a more general form (Eq. (7)). This assumes a heterogeneous dynamic response along the cable.

$$
\begin{aligned}
y(x, t)= & \sum_{n=1}^{N} C_{n}(x, t) \sin \left(\frac{n \pi x}{L}\right) \sin \left(2 \pi f_{n}(x, t) \sqrt{1-\xi_{n}^{2}(x, t)} t\right. \\
& \left.+\phi_{n}\right) \exp \left(-2 \pi f_{n}(x, t) \xi_{n}(x, t) t\right)
\end{aligned}
$$

In what follows, the following modal parameters related to the two first modes were extracted at three locations along the cable $(L / 2, L / 4$ and $L / 16)$, with:

- $f_{n}$, the natural frequency related to each mode $n$,

- $\xi_{n}$, the damping ratio related to each mode $n$,

- $C_{n}$, the amplitude of the signal in time domain related to each mode $n$,

- magnitude of the signal in frequency domain related to each mode $n$.

Their change over time is also studied, by using the tools presented in what follows.

\subsection{Post-treatment methodology}

\subsubsection{Identification of frequency and stiffness changes over time}

The Wigner-Ville transform is a signal processing tool. It enables to observe changes in energy distribution in the time-frequency plane, using a spectrogram [31]. In practice, improved Wigner-Ville transforms are used to remove interferences and boundary effects. In particular, the Smoothed Pseudo Wigner-Ville Transform (cf. Eq. (8)) was used in this study [32] and is defined by:

$S P W_{x}(t, f)=\int_{-\infty}^{\infty} h(\tau) \int_{-\infty}^{\infty} g(s-t) x\left(s+\frac{\tau}{2}\right) x^{*}\left(s-\frac{\tau}{2}\right) d s \exp (-2 i \pi f \tau) d \tau$

With $S P W_{x}$ the Smoothed Pseudo Wigner-Ville distribution, with $x$ the signal to analyze, $x^{*}$ the complex conjugate function of $x, g$ the time smoothing window, $h$ the frequency smoothing window in the time domain. Thus, contribution of each vibration mode and the corresponding natural frequency can be highlighted, during the whole

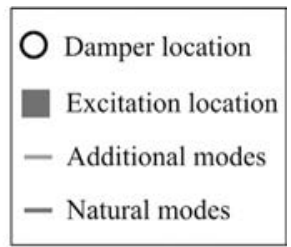

Fig. 7. Case-study 6 (damper and excitation locations at $L / 4$ ): Schematization of involved vibration modes. 

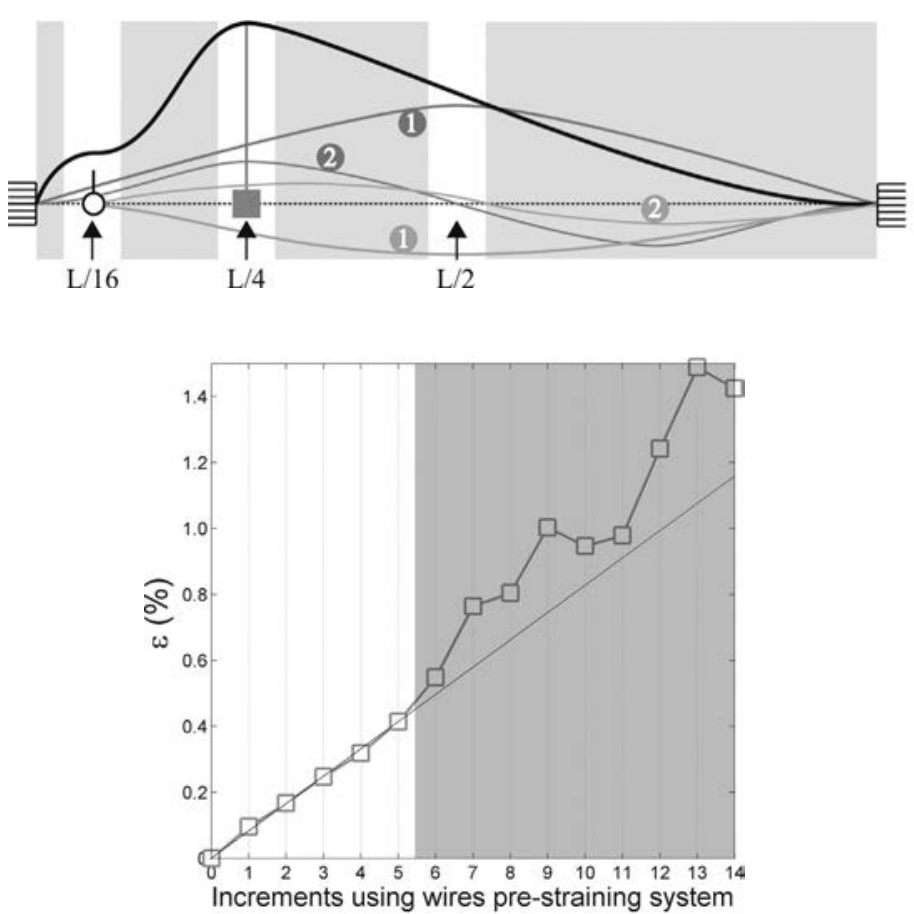

Fig. 9. Wire relative elongation according to the number of turnbuckle rounds, using prestraining system ("1-floor" damper located at $L / 2$ ).

\section{vibration signal.}

Natural frequencies are related to tension $T$ and bending stiffness $E I$ of the cable system, according to Eq. (5). Considering a serie of frequencies $f_{n}$ and their order $n, T$ and $E I$ can be evaluated by using iterative least square methods. Considering changes in modal frequencies $f_{n}(t)$ according to time, one can evaluate $T(t)$ and $E I(t)$ [33].

\subsubsection{Identification of damping ratio over time}

Damping ratio is evaluated using the logarithmic decrement method on the displacement signal $y_{n}(x, t)$ after filtering around $f_{n}$ (using Butterworth filter with a bandwidth of $0.5 \mathrm{~Hz}$ [34]) given by:

$\delta_{n}(x, t)=\ln \frac{y_{n}(x, t)}{y_{n}\left(x, t+T_{n}\right)}$

$T_{n}$ is the oscillation time-period. $\delta_{n}$ is directly linked with the modal damping ratio $\xi_{n}$ [35] and the expression can be simplified for low values of logarithmic decrements:

$\xi_{n}(x, t)=\frac{\delta_{n}(x, t)}{\sqrt{4 \pi^{2}+\delta_{n}(x, t)^{2}}} \approx \frac{\delta_{n}(x, t)}{2 \pi}$

With $f_{n}$ the natural frequency of the considered vibration mode.
Damper location

Fig. 8. Case-study 14 (damper at $L / 16$ and excitation at $L / 4)$ : Schematization of involved vibration modes.

Excitation location

- Additional modes

- Natural modes

\subsubsection{Estimation of the SMA wires relative elongation over time}

To link the material behaviour of the SMA wires to the cable system dynamic response, it is necessary to use their relative elongation, measured as explained before. The transformation yield stresses of both R-phase and martensite transformations are provided by the pseudodiagram in Fig. 2. A simple model is proposed to calculate the corresponding "transformation yield strains", according to the material temperature. Considering the strong non-linearity of the material behaviour, several assumptions enable to simplify the study.

In what follows, it is assumed that:

- Young modulus is taken constant and equal to the pure austenite modulus value $\left(E_{A}\right)$.

- Elongation field is homogeneous along the wire. Thus, the wire macroscopic strain is assumed to be equal to the wire relative elongation.

- Thermomechanical-coupling and self-heating due to material intrinsic dissipation are not taken into account.

- R-phase and martensite transformation yield stresses are linear function of the material temperature and are given by Eqs. (11) and (12), respectively, after Fig. 2.

$\sigma_{0}^{R}(T)=\mu^{R}\left(T-T^{*}\right)+\sigma^{R, *}$

$\sigma_{0}^{M}(T)=\mu^{M}\left(T-T^{*}\right)+\sigma^{M, *}$

where $\mu^{R}$ and $\mu^{M}$ are the slopes of Austenite to R-phase domain boundary and of austenite to martensite domain boundary, respectively, as provided by the pseudo-diagram (cf. Fig. 2). The values were averaged over forward and reverse transformations. $\sigma^{R, *}$ and $\sigma^{M, *}$ are the transformation yield stresses corresponding to the reference temperature of $T=T^{*}$. According to Fig. $2, \sigma_{0}^{M}(T)>\sigma_{0}^{R}(T)$, at room temperature, and $\mu^{R}>\mu^{M}$.

According to material temperature, three configurations can be identified, after Fig. 10:

1. " $\sigma_{0}^{M}(T)<\sigma_{0}^{R}(T)$ ", for "high temperature" values (cf. Fig. 10a). Only martensite transformation takes place:

$\varepsilon_{0}^{M}=\frac{\sigma_{0}^{M}}{E_{A}}$

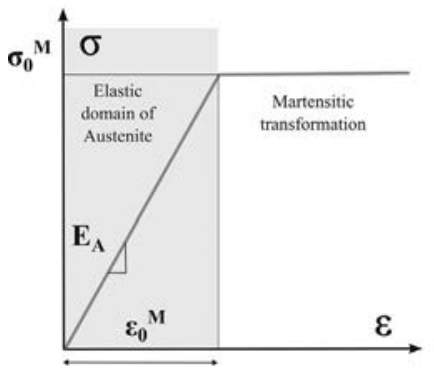

a)

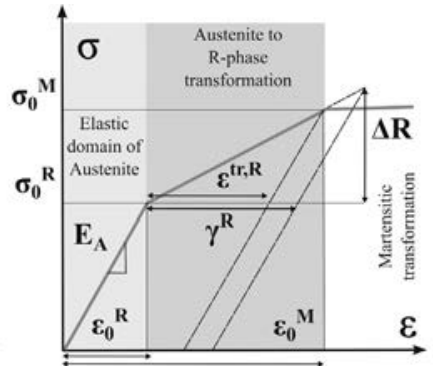

b)

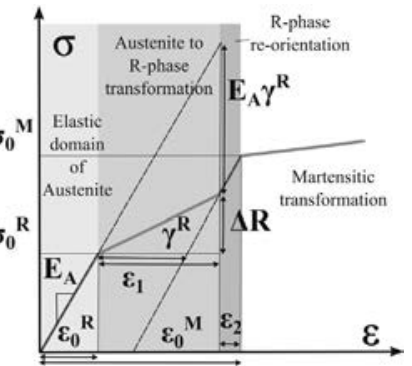

c)

Fig. 10. Analytic model for prediction of strain level triggering phase transformations: (a) $T=T_{1}$; (b) $T=T_{2}<T_{1}$; (c) $T=T_{3}<T_{1}$. 
2. " $\sigma_{0}^{M}(T)<\sigma_{0}^{R}(T)+\Delta R$ ", for "room temperature" values (cf. Fig. 10b). Martensite transformation starts before the end of R-phase transformation:

$$
\left\{\begin{array}{l}
\varepsilon_{0}^{R}=\frac{\sigma_{0}^{R}}{E_{A}} \\
\varepsilon^{t r, R}=\gamma^{R}\left(\frac{\sigma_{0}^{M}-\sigma_{0}^{R}}{\Delta R}\right) \\
\varepsilon_{0}^{M}=\varepsilon^{t r, R}+\frac{\sigma_{0}^{M}}{E_{A}}
\end{array}\right.
$$

where $\varepsilon^{t r, R}$ is the effective strain due to R-phase transformation, and $\gamma^{R}=\varepsilon_{\text {max }}^{t r, R}$ is its maximum value.

3. " $\sigma_{0}^{M}(T)>\sigma_{0}^{R}(T)+\Delta R$ ", for "low temperature" values (cf. Fig. 10c). R-phase transformation ends before the start of martensite transformation:

$$
\left\{\begin{array}{l}
\varepsilon_{0}^{R}=\frac{\sigma_{0}^{R}}{E_{A}} \\
\varepsilon_{1}=\frac{\Delta R+E_{A} \gamma_{R}}{E_{A}} \\
\varepsilon_{2}=\frac{\sigma_{0}^{M}-\sigma_{0}^{R}-\Delta R}{E_{A}} \\
\varepsilon_{0}^{M}=\varepsilon_{0}^{R}+\varepsilon_{1}+\varepsilon_{2}
\end{array}\right.
$$

Identification of parameters given in Table 3 is detailed in [18].

\section{Results}

\subsection{Interest of SMA}

This first part is to qualitatively justify the choice of NiTi-based SMA, by using the "1-floor" damper. A damper using steel wires instead of NiTi wires and the "1-floor" SMA-based damper are compared in the case-study 2 (damper location at $L / 2$ and excitation location at $L / 4$ ). Diameter of steel wires is similar but material stiffness in tension is more than three times higher in comparison with NiTi wires one (elastic modulus of about $200 \mathrm{MPa}$ against $57 \mathrm{MPa}$ for SMA at austenite state). Time-domain signals and frequency spectra are presented at several locations along the cable $(L / 2, L / 4, L / 16)$, in Figs. 11 and 12 , respectively.

For both dampers, damping was significant at $L / 2$, due to a high contribution of the first vibration mode. For both dampers, the decrease in amplitude was much lower at $L / 4$ and $L / 16$, where contribution of the second mode remains significant, once the first mode fully damped. Indeed, the damper was located at the "antinode" of the first mode and at the "node" of the second one.

Using the steel wires-based damper, the first mode and the oddnumber modes were totally removed whereas the even-number modes were not damped, according to frequency spectra (cf. Fig. 11). In these configurations, the cable response demonstrated a unstable self-perpetuating behaviour at $L / 4$ and $L / 16$, because of a strong local increase in bending stiffness at the damper location during a half-period of oscillation (according working sense of the "1-floor" damper). Indeed, the device added a transverse stiffness, without dissipating any energy. The damper can be considered as an "additional node", that induced additional vibration modes. Furthermore, one have to notice that a strong

Table 3

Parameters of the simplified model.

\begin{tabular}{lcccc}
\hline Parameter & $\mu^{M}$ & $\mu^{R}$ & $\sigma^{M, *}$ & $\sigma^{R, *}$ \\
Value & $13.5 \mathrm{MPa}$ & $6.3 \mathrm{MPa}$ & $465.4 \mathrm{MPa}$ & $276.1 \mathrm{MPa}$ \\
& $E_{A}$ & $\Delta R$ & $\gamma_{R}$ & $T^{*}$ \\
Parameter & $57 \mathrm{GPa}$ & $220 \mathrm{MPa}$ & 0.002 & $298 \mathrm{~K}$ \\
Value & & & & \\
\hline
\end{tabular}

loading or displacement submitted to the cable could entail permanent strain of steel wires, due to the permanent phenomenon of plasticity. This could change initial pre-strain and then reduce damping efficiency.

Due to superelasticity effect, SMA wires are prevented from this phenomenon. The SMA-based damper is not more efficient than the steel-based one. However, the lower stiffness add is a real advantage, regarding load transfer to the damper fixations. Only the first mode and the odd-number modes were damped, but they were not totally removed (cf. Fig. 12) as in Fig. 11. An increase in frequency from $2.3 \mathrm{~Hz}$ to $3.2 \mathrm{~Hz}$ by setting-up the damper was observed, that demonstrated an increase of bending stiffness of the cable. Eventually, use of steel wires is not considered as relevant: only results related to SMA wires are presented in what follows.

\subsection{Efficiency of SMA-based damper along the whole cable}

This part is dedicated to the study of the spatial distribution (along the whole cable) in damping efficiency for the "1-floor" damper. First, case-study 6 is considered (damper and excitation locations at $L / 4$ ). In this case-study, the damper is located at the "antinode" of the second mode. A high damping ratio related to the second mode is logically expected. Transverse displacement along the cable versus time is given in Fig. 13.

Wherever the location along the cable, a significant effect of the damping device was observed. Two points can be noticed, when compared to the configuration whithout any damper: (i) the initial displacement amplitude was strongly limited since the first oscillation and (ii) the decrease in amplitude was accelerated. The logarithmic slope decrement method was applied on signals filtered around $f_{1}$ (displacement at $L / 2$ ) and $f_{2}$ (displacement at $L / 4$ ). Damping regimes, related to the two first vibration modes, were estimated from the linear parts of the logarithmic slope decrement according to time and are presented in Figs. 14 and 15. For more details, identification of damping regimes in case-study 6 is higlighted in the discussion part. Approximate duration of each damping regime is directly indicated in Figs. 14 and 15. Approximate value of modal frequencies, during the whole signal and whatever the working regime, is also provided. Change in modal frequencies value during the amplitude vibration mitigation will be discussed further.

Thus, three damping regimes, related to the first mode, have been identified: a "highly effective" damping regime, then an "effective" damping regime and lastly a "lowly effective" damping regime. During the free vibration, damping regimes are less and less efficient but longer and longer. The first and most efficient regime is difficult to measure, due to side-effects induced by numerical filtering. Along the whole cable, duration of damping regimes seems to be homogeneous. Damping ratio values corresponding to the second regime are above the recommanded value of $\xi_{\text {Ifsttar }}^{c r}$. The third one is below $\xi_{\text {Ifsttar }}^{c r}$ but much higher than values highlighted without any damper.

Two damping regimes can be observed for the second mode, after Fig. 15. Indeed, the corresponding damping efficiency was lower because the contribution of the first mode was higher than the contribution of the second one, even at $L / 4$. Due to the set-up of the damper, the second mode could have changed. It would explained why the latter can be observed at $L / 2$ ("node" related to mode 2), unlike in the configuration without any damper.

The same analysis can be done on case-study 14 (damper location at $L / 16$ and excitation location at $L / 4$ ), for the "1-floor" damper. The damper was much closer to one of the cable anchoragings, which represents a more realistic configuration. The cable response related to several locations along the cable is given in Fig. 16 and damping ratio distribution along the cable is given in Figs. 17 (mode 1) and 18 (mode 2).

The closer the damper to the anchoraging, the lower the transverse displacement amplitude at the damper location and so the lower the 

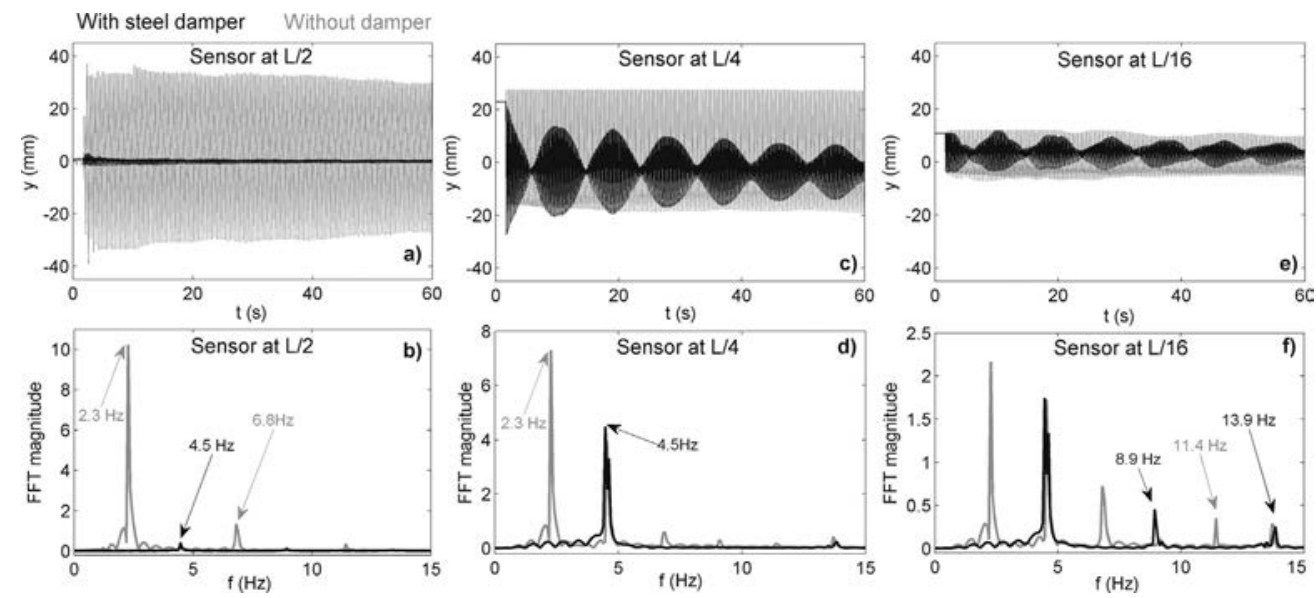

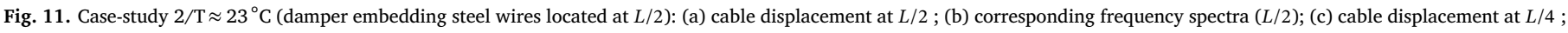
(d) corresponding frequency spectra $(L / 4)$; (e) cable displacement at $L / 16$; (f) corresponding frequency spectra $(L / 16)$.

dissipated energy. It is confirmed by curves provided in Fig. 16, when compared with Fig. 13.

Nevertheless, a relatively good damping efficiency can be observed during the first part of the signal. In particular, the damping was significant at $L / 16$, especially regarding the mode 2 (cf. Fig. 18) because of a higher contribution than for the mode 1. After [11], for $a / L=1 / 16 \approx 6 \%, \xi_{L / 16}^{o p t} \approx 3 \%$. Thus, damping ratio performed by the " 1 floor" SMA-based damper is around 3-4 times lower than damping ratio performed by an optimal viscous damper.

Eventually, a global efficiency has been observed. It is function of the damper location distance from "antinodes" of the considered vibration mode. Local effects are added to the global one, due to a local increase in bending stiffness around the damper and near the two cable anchoragings.

\subsection{Effect of testing temperature}

The effect of testing temperature on damping capacity provided by the "1-floor" device is highlighted in this section. As shown in Fig. 4, a decrease in temperature induces an increase in material loss factor. This assumption has to be verified using cable vibration tests. The case-study 14 (damper location at $L / 16$ and excitation location at $L / 4$ ) was realized at "high" and at "low" temperatures. The related curves are presented in Fig. 19.

Obviously, a decrease in temperature triggers an acceleration of the cable displacement mitigation. The initial amplitude value after cable releasing seems to be unchanged. Thus, temperature seems to have a slight effect on additional stiffness added by damper device, but a high impact on dissipated energy. Thus, effects of temperature on damping capacity are confirmed ad hoc, by using the "1-floor" damper. For a given case-study, effects of the NiTi wires dissipation on damping of the whole structure are clearly highlighted. Pre-straining of embedded wires can be considered as a way to compensate effects of ambient temperature, if a minimal fatigue life has to be guaranteed. For instance, a lower pre-straining can be imposed in winter, because the transformation yield stresses (and consequently the transformation yield strains) are lower than in summer.

\subsection{Increase in damper dissipated energy per cycle}

In this part, efficiency of "1-floor" and "2-floors" dampers are eventually compared. To improve damping capacity provided by NiTi wires for a given displacement amplitude, several ways exist. One of them consists in shortening wire length: for a given displacement amplitude, the wire relative elongation is higher and the dissipated energy is naturally increased. An other one consists in conceiving a new system to enable a continuous working, whatever the sense of the cable displacement. Both ways are taken into account in the "2-floors" damper version. "1-floor" and "2-floors" dampers are compared in Figs. 20 and 21 , corresponding to the case-studies 6 and 14 (damper location at $L / 4$ or $L / 16$, respectively, and excitation location at $L / 4$ ).

One can observe a significant increase in damping, triggered by the "2-floors" damper. Initial amplitude is not similar with both dampers.
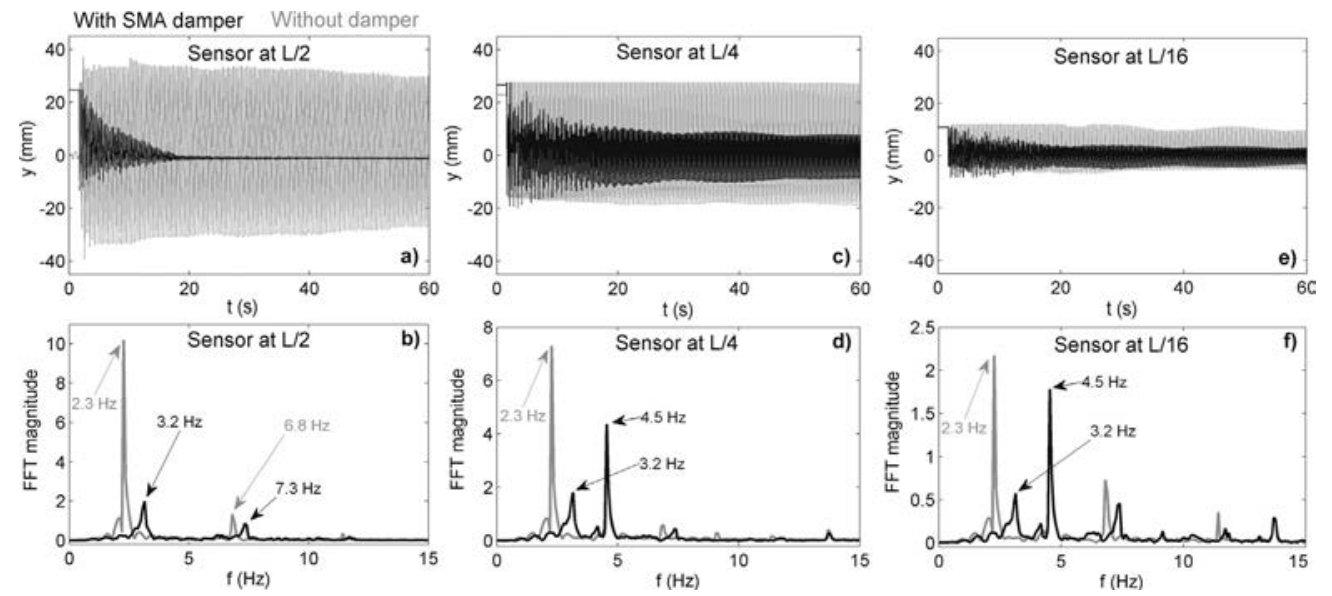

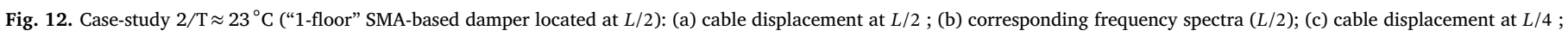
(d) corresponding frequency spectra $(L / 4)$; (e) cable displacement at $L / 16$; (f) corresponding frequency spectra $(L / 16)$. 


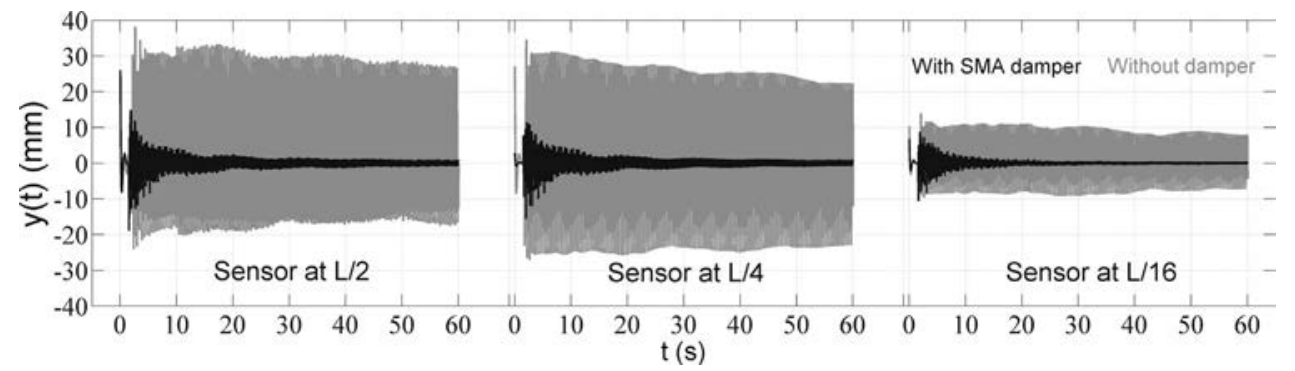

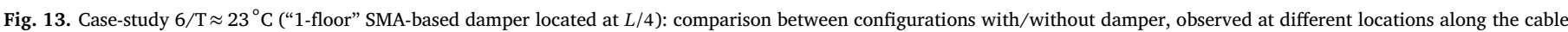
$(L / 2, L / 4$ and $L / 16)$.

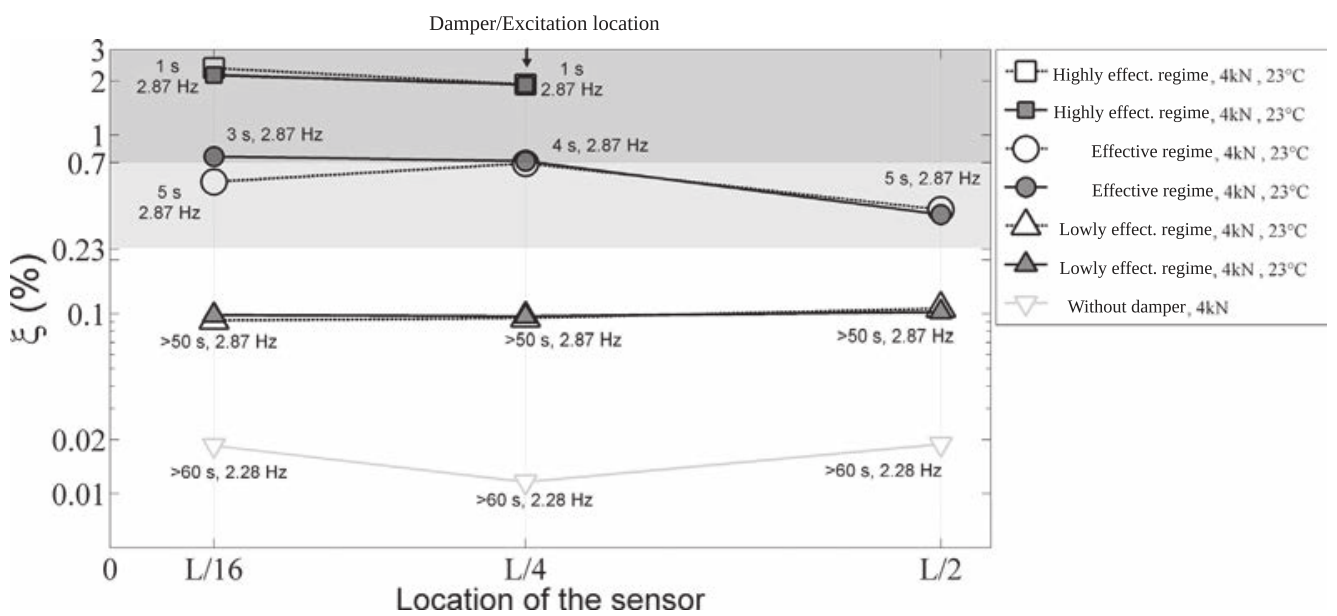

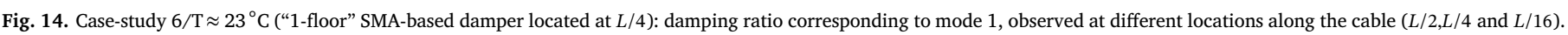

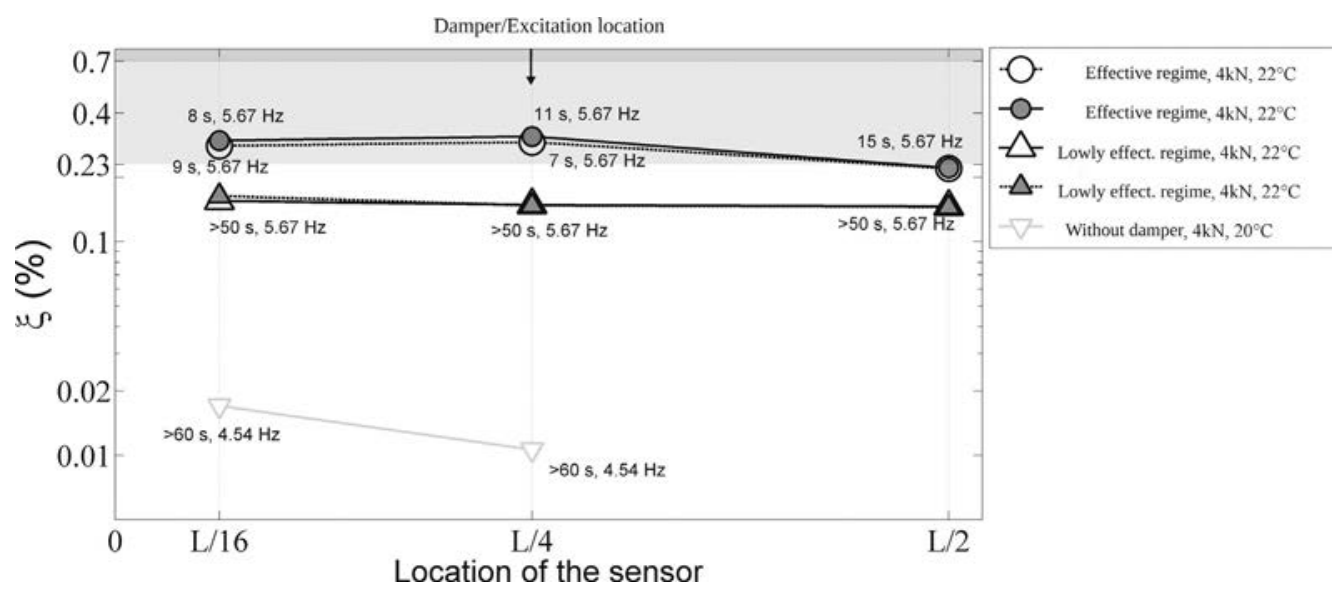

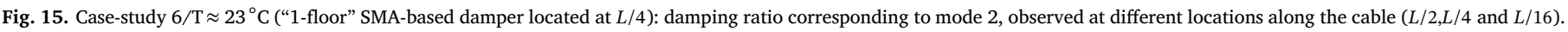

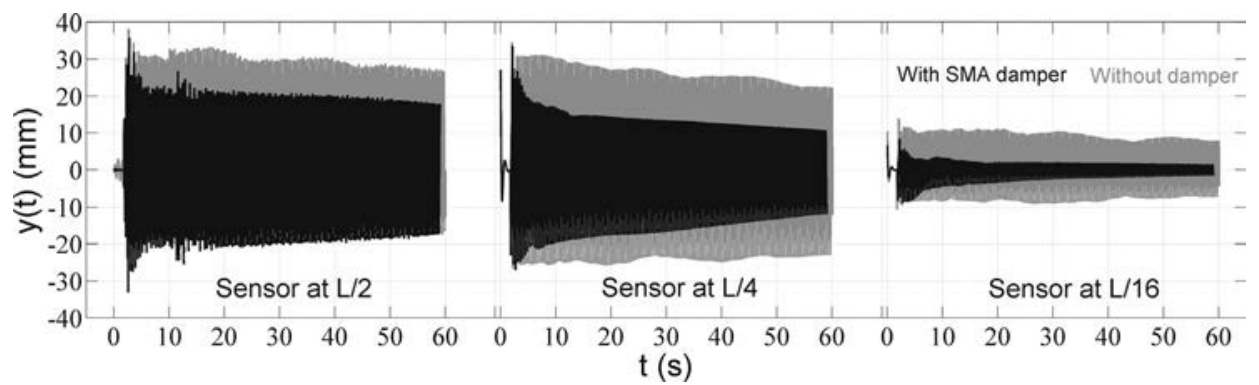

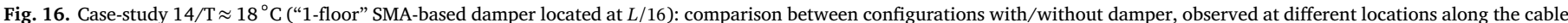
$(L / 2, L / 4$ and $L / 16)$. 


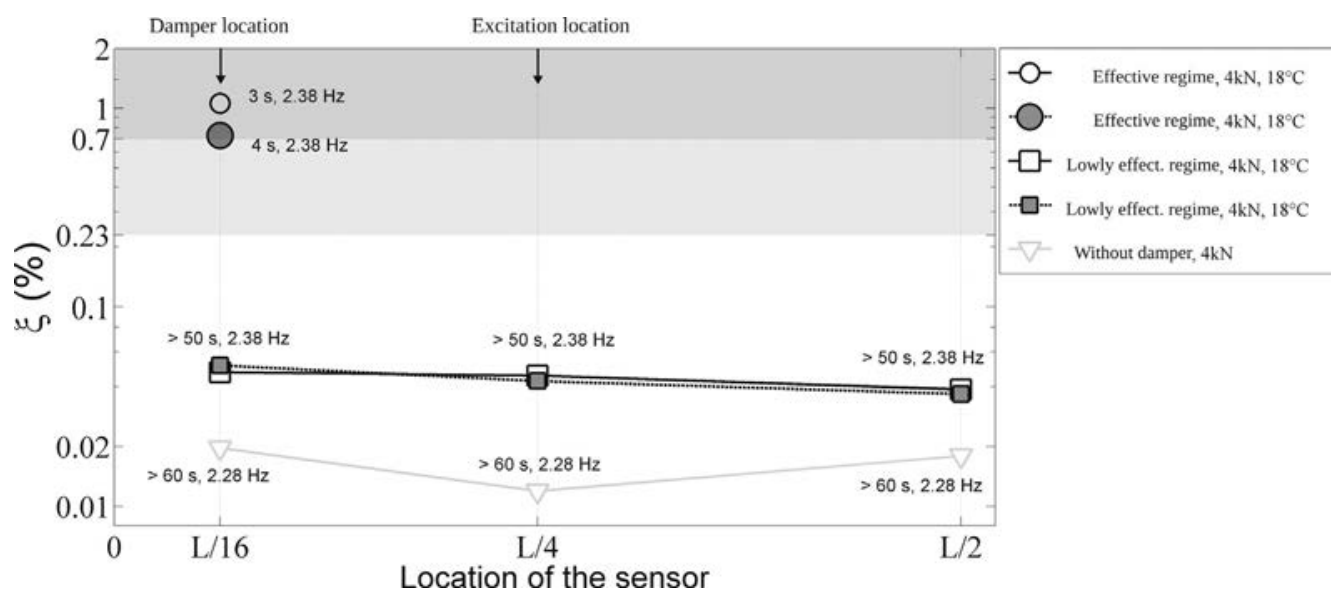

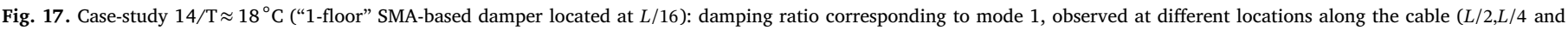
$L / 16)$.

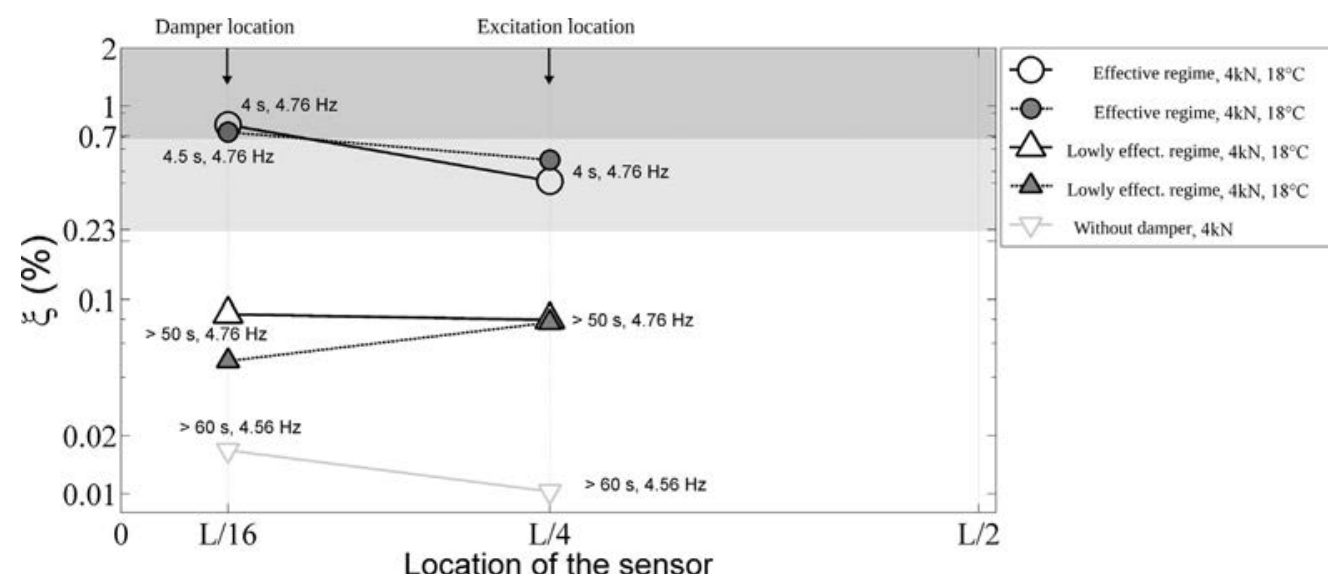

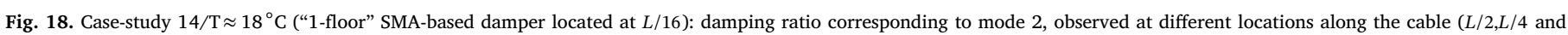
$L / 16)$.

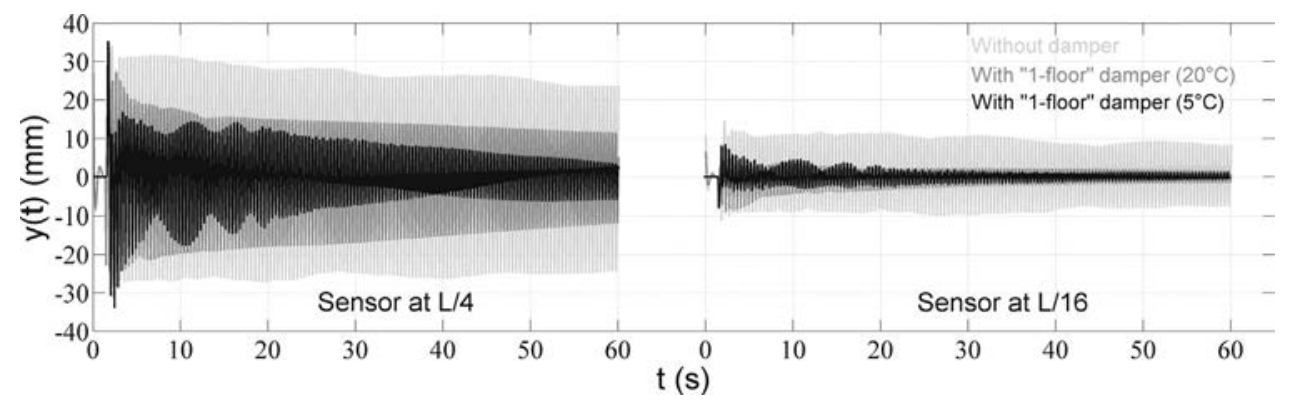

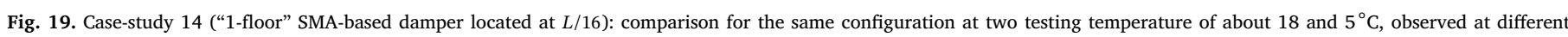
locations along the cable $(L / 4$ and $L / 16)$.

Indeed, excitation was inhibited by the "2-floors" damper, that increased the initial bending stiffness of the cable. Furthermore, each part of the two wires embedded in the new device and alternatively subjected to stretching is twice shorter in the second version than in the first one. Thus, relative elongation is higher in this configuration, for a given displacement value of the cable. This could be detrimental regarding fatigue life of NiTi wires, even if the benefit is obvious regarding fatigue life of the cable. A study focused on SMA fatigue properties is necessary to determine if a large wire elongation followed by a fast mitigation of the cable vibration amplitude is more acceptable than a moderate wire elongation followed by a slow mitigation of the cable vibration amplitude. Eventually, a new damping device is proposed and its efficiency is really promising.

\section{Discussion}

\subsection{Change in vibration frequencies and in cable apparent bending stiffness}

This section aim is to link cable damping capacity and the whole system stiffness to the behaviour of the NiTi wires embedded in the damper devices. Indeed, the results of experimental tests have demonstrated a complex dynamic response of the whole system. A better understanding of the phenomena involved in NiTi material is necessary to explain notable results such as changes in damping ratio during mitigation of the cable vibration amplitude. In this part, only the "1floor" device, which is the most basic device, is used in order to more carefully interpret the results. The case-study is 6 . 


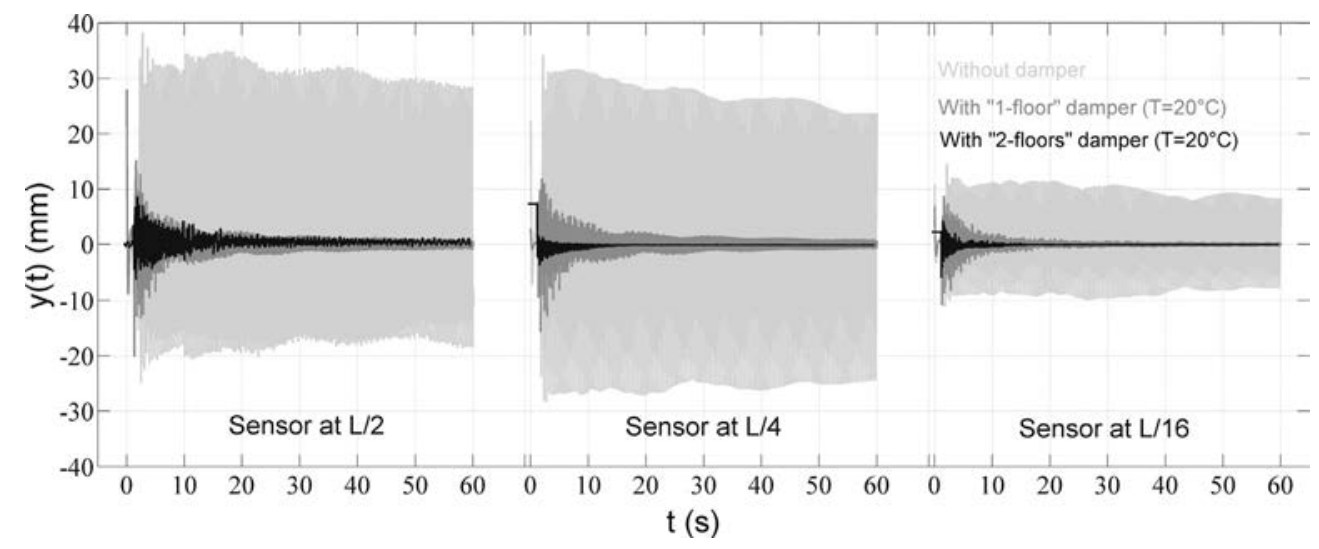

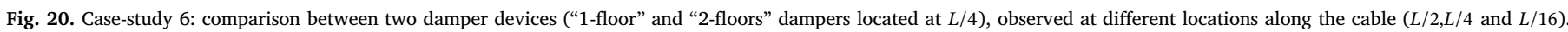

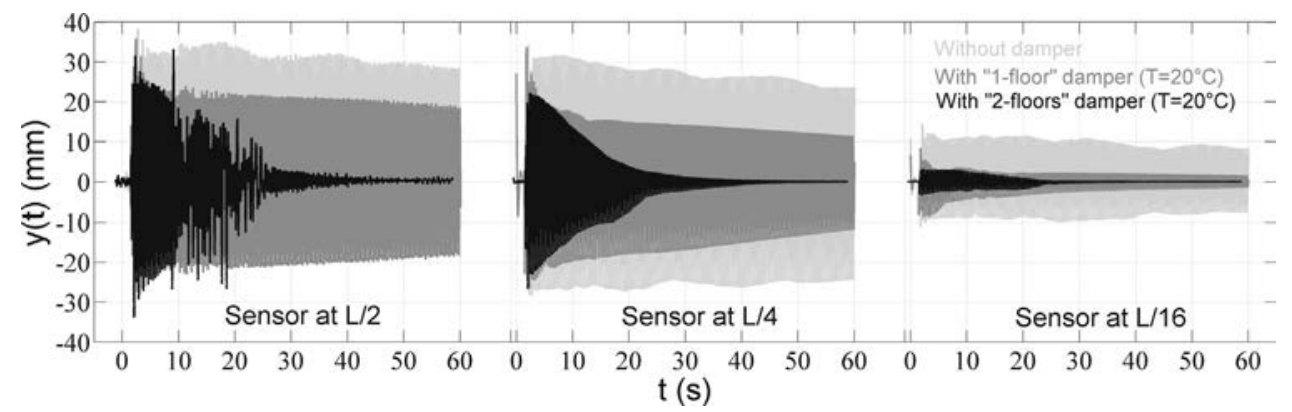

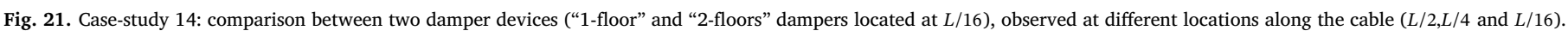

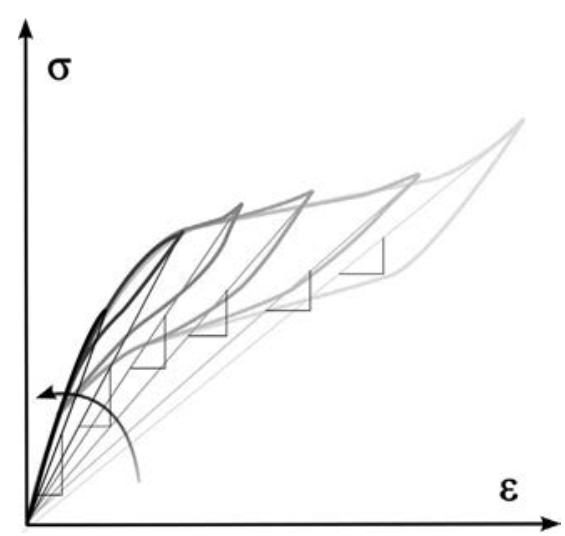

Fig. 22. Description of changes in apparent material stiffness during vibration amplitude mitigation.

Assuming that natural frequency is non-linearly related to the cable bending stiffness increase (cf. Eq. (5)), frequency changes during mitigation can be a qualitative indicator of working damping regimes of the device. Indirectly, it can be related to dissipation "regimes" of NiTi wires working. A decrease in cable displacement during mitigation can be schematically represented as in Fig. 22, in the material behaviour point of view.

At each cycle, average stiffness is assumed to be the right line slope between the figure origin and the maximal strain point (cf. Fig. 22). Thus, the material stiffness generally increases during the mitigation of the cable vibration amplitude. That naturally locally increases the additional bending stiffness of the cable, close to the damper location.

Both logarithmic slope decrement and frequency versus time related to mode 1 and mode 2 are presented in Figs. 23 and 24, respectively. Curves corresponding to two tests are presented to illustrate good reproducibility of the experiments.

Curves are deteriorated due to filtering around considered modal frequency. Side effects are not considered (cf. hatchings in Fig. 23). Time " 0 " corresponds to the cable releasing. Three damping regimes can be clearly observed in Fig. 23a. The two first "highly effective" and "effective" damping regimes (to about $10 \mathrm{~s}$ ) correspond to an increase in natural frequency as shown in Fig. 23b, what is in accordance with a non linear behaviour due to phase transformation. During the third and "lowly effective" regime, the frequency value is constant, what is in accordance with the elastic behaviour of the pure austenite phase. Study of frequency changes enables to highlight increase in additional bending stiffness. More particularly, a transition between a non linear and a linear behaviour of embedded NiTi wires may be highlighted. However, the transition between the first "highly effective" and the second "effective" regime is not automatic, because of a strongly nonlinear relation induced by a localized increase in bending stiffness of the cable.

All these observations are confirmed by a similar study around the second vibration mode (cf. Fig. 24).

Only two regimes have been identified from the logarithmic decrement method (cf. 24a). However, the transition between the two first regimes is made easier by analyzing frequency changes (cf. 24b).

Frequency changes have been extracted on several modes to provide bending stiffness changes of the cable during the mitigation of the cable vibration amplitude, as presented in Fig. 25. The comparison with the configuration without any damper demonstrates an increase in stiffness from $20 \%$ (initially) to $30 \%$ (after displacement stabilization). The corresponding increase in frequency was from 20\% (initially) to $25 \%$ (after displacement stabilization) for the two first modes, as described above.

Clearly, highlighting of the transition between two damping regimes is much easier while analyzing frequency changes than linear parts of logarithmic decrement, according to time.

\subsection{Estimation of damping capacity ranges from wires elongation}

The previous section directly provides information about increase in 

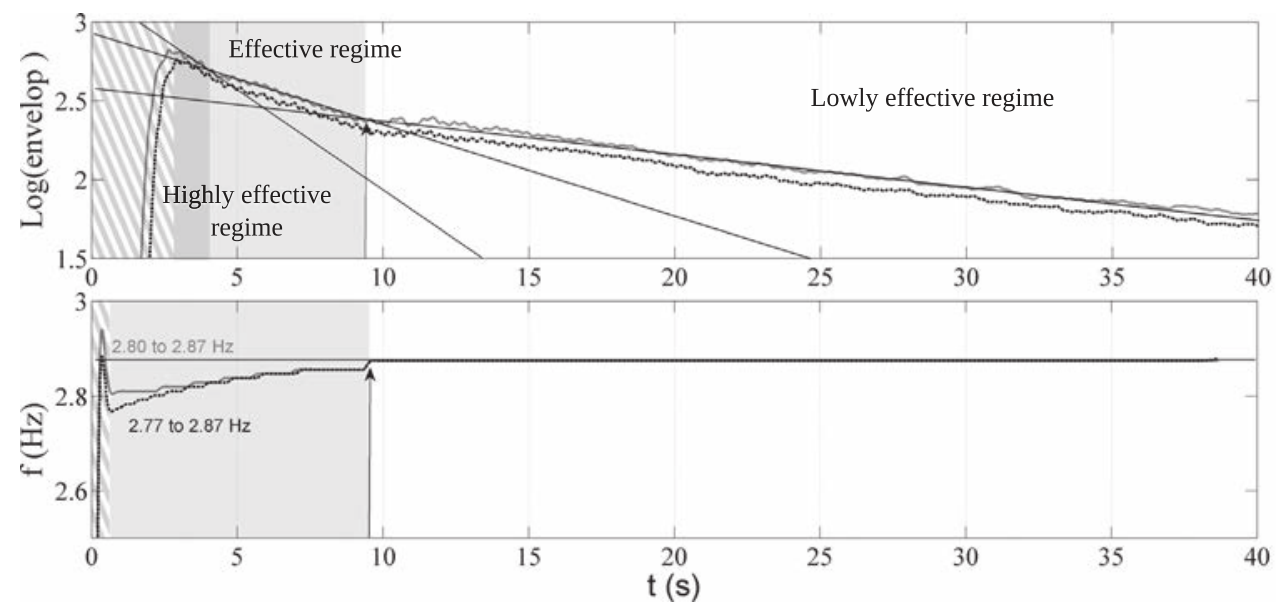

b)

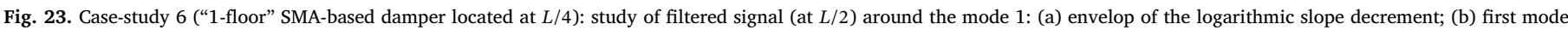
frequency changes.
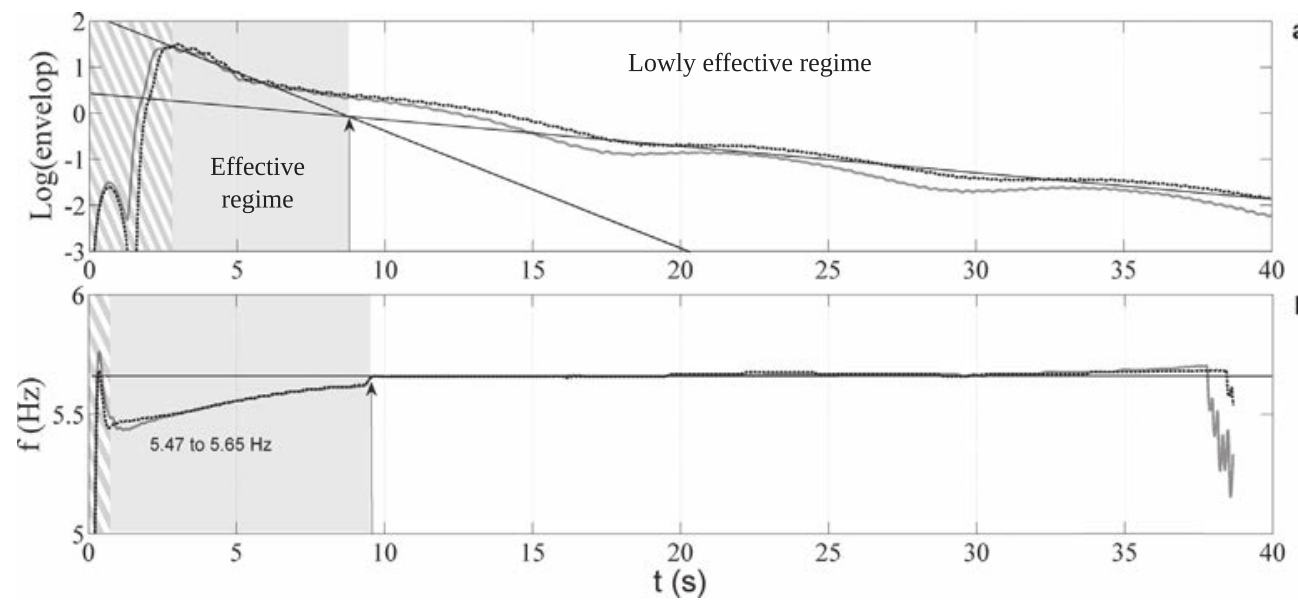

a)

b)

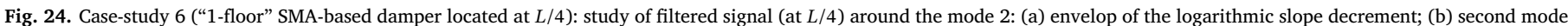
frequency changes.

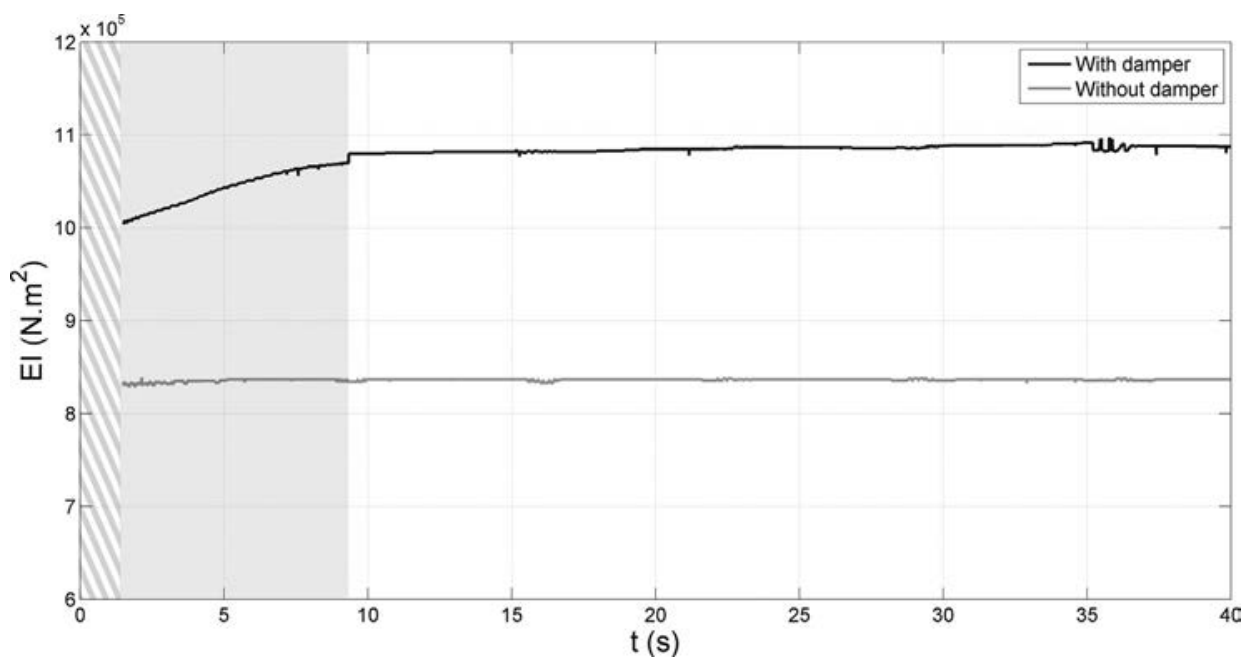

Fig. 25. Case-study 6 ("1-floor" SMA-based damper located at $L / 4$ ): changes in bending stiffness in average according to time, obtained from modal frequency changes.

bending stiffness of the cable. The purpose of this section is to draw a parallel between the latter and the material behaviour. Relative elongation of damper wires is available thanks to laser sensor measurements and it is possible to determine "transformations yield strains" to deduce NiTi wires working regimes, using the simple analytic model presented in Section 3.4.3. The same case-study is so considered. Relative elongation of the wires over time is presented in Fig. 26, while strain values suspected to initiate martensite or R-phase transformation are indicated.

Three "regimes" can be observed. Few cycles involving martensite transformation, which means significant dissipation, is related to the first regime. The second regime is clearly linked to R-phase 


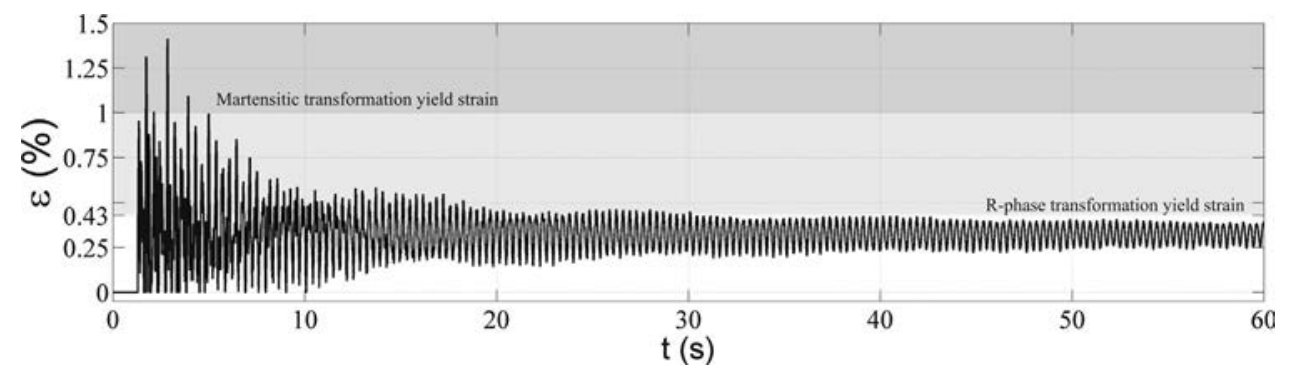

Fig. 26. Case-study 6 ("1-floor" SMA-based damper located at $L / 4$ ): prediction of damping capacity regimes using simplified model.

transformation domain, which provides a moderate damping capacity. The end of the second regime is difficult to precisely define, because of slow changes in wires strain. The faster the decrease in elongation, the easier the determination of regimes. After $30 \mathrm{~s}$ from the cable releasing, R-phase appearance is clearly not possible, which introduces the third and less efficient "regime", where only internal frictions in the austenite NiTi microstructure and in the complex stranded-wires structure of the cable can be considered as dissipation sources. The transition could have happened before, because of an expected increase in material temperature (induced by mechanical energy conversion into heat), which would have induced an increase in "transformation yield strain". As seen before, R-phase is very temperature-sensitive.

This method is interesting because it is directly related to material behaviour. However, the discussion shows limitations of using the proposed simplified model.

\section{Conclusion}

In this paper, two NiTi based dampers developped in Ifsttar laboratory are presented. From realistic experiments using a vibration bench dedicated to civil engineering cables, we can draw the following conclusions:

1. Both dampers have demonstrated a good efficiency, even for low vibration amplitudes near the cable anchorages (which is a realistic configuration), in addition of the promising results presented in $[14,17]$. The "1-floor" damper was less efficient but a shorter fatigue life of NiTi wires embedded in the "2-floors" damper is expected.

2. According to several case-studies, the positive effect of the "1-floor" damper was effective along the whole cable. It is related to vibration modes and their "antinode" location, depending on the damper location.

3. Temperature effect on SMA-based damper was observed and this is in accordance with data related to specific material properties.

A discussion enables to demonstrate the complex but direct link between NiTi wires behaviour and vibration response of the system "cable + damper" from the cable transverse displacement signal:

i. Different damping regimes can be identified from conventional tools applied on vibration signals in time-domain.

ii. Different damping "regimes" can be identified, observing frequency changes deduced from vibration signals. It is related to secant stiffness modulus changes, which means it is related to material state and microstructure.

iii. A simple model enables to qualitatively predict three damping regimes, previously identified in [17] and confirmed by this study. The results are in good agreement with the assumption of several phase transformations (including martensite and R-phase ones), which are sources of dissipation.

The well-known behaviour heterogeneity (localization effects) as well as significant rate effects in NiTi alloys make results interpretation difficult. Thus, the development of a numerical tool, such as finite element simulations using a relevant superelastic material law, is needed. It would enable to understand coupling effects, by discoupling the contributions of each involved physical phenomenon. First positive findings concerning numerical simulations are partially available in $[18,36]$.

\section{Acknowledgements}

To Daniel Bruhat, Richard Michel, Jean-François David and Yannick Falaise (SMC/Ifsttar) for their participation in the experimental set-up, the development of both considered devices and the measurements.

\section{References}

[1] Matsumoto M, Shiraishi N, Kitazawa M, Knisely C, Shirato H, Kim Y, et al. Aerodynamic behavior of inclined circular cylinders-cable aerodynamics. J Wind Eng Ind Aerodyn 1990;33(12):63-72.

[2] Matsumoto M, Shiraishi N, Shirato H. Rain-wind induced vibration of cables of cable-stayed bridges. J Wind Eng Ind Aerodyn 1992;43(1):2011-22.

[3] Matsumoto M, Saitoh T, Kitazawa M, Shirato H, Nishizaki T. Response characteristics of rain-wind induced vibration of stay-cables of cable-stayed bridges. J Wind Eng Ind Aerodyn 1995;57(23):323-33.

[4] Matsumoto M, Daito Y, Kanamura T, Shigemura Y, Sakuma S, Ishizaki H. Windinduced vibration of cables of cable-stayed bridges. J Wind Eng Ind Aerodyn 1998;74:1015-27.

[5] Matsumoto M, Yagi T, Shigemura Y, Tsushima D. Vortex-induced cable vibration of cable-stayed bridges at high reduced wind velocity. J Wind Eng Ind Aerodyn 2001;89(78):633-47.

[6] Zuo D, Jones NP. Interpretation of field observations of wind - and rain-wind-induced stay cable vibrations. J Wind Eng Ind Aerodyn 2010;98:73-87.

[7] Chaussin R, Bournand Y, Chabert A, Demilecamps L, Demonte A, Jartoux P, et al. CIP recommendations on cable stays. Report, SETRA; Nov 2001.

[8] Caetano E de S. Cable vibrations in cable-stayed bridges. Structural engineering documents. Zurich, Switzerland: IABSE-AIPC-IVBH; 2007.

[9] Jensen CN. Optimal damping of stays in cable-stayed bridges for in-plane vibrations. J Sound Vib 2002;256(1):499-513.

[10] Weber F, Distl H. Amplitude and frequency independent cable damping of Sutong Bridge and Russky Bridge by magnetorheological dampers. Struct Control Hlth 2015;22(2):237-54.

[11] Krenk S. Vibrations of a taut cable with an external damper. J Appl Mech $2000 ; 67: 772$

[12] Shi X, Zhu S, Li J-Y, Jr BFS. Dynamic behavior of stay cables with passive negative stiffness dampers. Smart Mater Struct 2016;25(7):075044.

[13] Weber F, Distl H. Semi-active damping with negative stiffness for multi-mode cable vibration mitigation: approximate collocated control solution. Smart Mater Struct 2015;24(11):115015.

[14] Torra V, Auguet C, Isalgue A, Carreras G, Terriault P, Lovey FC. Built in dampers for stayed cables in bridges via SMA. The SMARTeR-ESF project: a mesoscopic and macroscopic experimental analysis with numerical simulations. Eng Struct 2013;49:43-57.

[15] Janocha H. Adaptronics and smart structures. Springer-Verlag; 2007.

[16] DesRoches R, Delemont M. Seismic retrofit of simply supported bridges using shape memory alloys. Eng Struct 2002;24(3):325-32.

[17] Dieng L, Helbert G, Arbab-Chirani S, Lecompte T, Pilvin P. Use of shape memory alloys damper device to mitigate vibration amplitudes of bridge cables. Eng Struct 2013;56(0):1547-56.

[18] Helbert G, Saint-Sulpice L, Chirani SA, Dieng L, Lecompte T, Calloch S, et al. Experimental charaterisation of three-phase NiTi wires under tension. Mech Mater 2014;79:85-101.

[19] Zhu J, Wang Y, Shen H. J Phys 1983;44(C9):235.

[20] Humbeeck JV. Damping capacity of thermoelastic martensite in shape memory alloys. J Alloys Comp 2003;355(1-2):58-64.

[21] Soul H, Isalgue A, Yawny A, Torra V, Lovey FC. Pseudoelastic fatigue of NiTi wires: frequency and size effects on damping capacity. Smart Mater Struct 
2010;19(8):085006.

[22] Piedboeuf MC, Gauvin R, Thomas M. Damping behaviour of shape memory alloys: strain amplitude, frequency and temperature effects. J Sound Vib 1998;214(5):895-901.

[23] He Y, Yin H, Zhou R, Sun Q. Ambient effect on damping peak of NiTi shape memory alloy. Mater Lett 2010;64(13):1483-6.

[24] Morin C, Moumni Z, Zaki W. Thermomechanical coupling in shape memory alloys under cyclic loadings: experimental analysis and constitutive modeling. Int $\mathrm{J}$ Plasticity 2011;27(12):1959-80.

[25] Helbert G, Saint-Sulpice L, Chirani SA, Dieng L, Lecompte T, Calloch S, et al. A uniaxial constitutive model for superelastic NiTi sma including R-phase and martensite transformations and thermal effects. Smart Mater Struct 2017;26(2):025007.

[26] Saint-Sulpice L, Arbab-Chirani S, Calloch S. Thermomechanical cyclic behavior modeling of Cu-Al-Be SMA materials and structures. Int J Solids Struct 2012;49(9):1088-102.

[27] Poston RW. Cable-stay conundrum. Civ Eng 1998:68(8):58-61.

[28] Main J, Jones N. Evaluation of viscous dampers for stay-cable vibration mitigation. J Bridge Eng 2001;6(6):385-97.
[29] Wang X, Ni Y, Ko J, Chen Z. Optimal design of viscous dampers for multi-mode vibration control of bridge cables. Eng Struct 2005;27(5):792-800.

[30] Morse P, Ingard K. Theoritical acoustics. Princeton University Press; 1968.

[31] Neild S, McFadden P, Williams M. A review of time-frequency methods for structural vibration analysis. Eng Struct 2003;25(6):713-28.

[32] Auger F, Gonçalvès P, Lemoine $\mathrm{O}$, Flandrin P. Time-frequency toolbox for Use with Matlab; 1995-1996.

[33] Yamagiwa I, Utsuno H, Endo K, Sugii K, Morimoto T. Application of the identification of tension and flexural rigidity at once to the bridge cables. J Constr Steel 1997;5:15-22.

[34] Butterworth S. On the theory of filter amplifiers. Wirel Eng 1930;7:536-41.

[35] Shabana A. Theory of vibration: an introduction, mechanical engineering series. New York: Springer; 1995

[36] Helbert G, Saint-Sulpice L, Chirani SA, Dieng L, Pilvin P. Strain rate effects and Rphase influence on NiTi-based SMA wires dissipation illustrated by a civil engineering application issue. In: The $9^{\text {th }}$ international conference on the mechanics of time dependent materials, Montreal, Canada; 2014. 